\title{
A economia política do complexo Soja-Carne Brasil-China $^{1}$
}

\section{The political economy of the Brazil-China Soy-Meat Complex}

\author{
Fabiano Escher $^{1}$ (i) e John Wilkinson ${ }^{2}$
}

Resumo: $\mathrm{O}$ argumento desenvolvido no artigo, baseado na abordagem dos regimes alimentares, é que a formação do "complexo soja-carne Brasil-China", a partir do início dos anos 2000, representa uma mudança policêntrica nas relações agroalimentares globais, impulsionada pelos interesses das corporações do agronegócio e indústrias alimentares, bem como dos estados nacionais, em uma direção Sul/Oriente, que desafia o poder estabelecido das grandes corporações transnacionais do Atlântico Norte. Com base na literatura contemporânea em economia política agrária e numa combinação de dados quantitativos e qualitativos, são identificadas as origens, características e dinâmicas do complexo soja-carne Brasil-China através de uma análise comparativa e relacional. Após uma breve revisão teórica, se examina a mudança nos hábitos alimentares e dietas de classe e a reestruturação das indústrias de carnes (especialmente suína) e rações do lado chinês, como polo importador, e o boom das commodities e a expansão na produção, na área plantada e nas exportações de soja do lado brasileiro, como polo exportador. Entretanto, apesar da importância do comércio bilateral na dinâmica do complexo soja-carne Brasil-China, recentemente tem havido também um crescente afluxo de investimentos chineses no agronegócio brasileiro. Nas conclusões, além de aspectos estritamente econômicos, aspectos políticos do complexo soja-carne Brasil-China são discutidos.

Palavras-chaves: complexo Soja-Carne Brasil-China, regime alimentar, agronegócio, comércio agrícola internacional, investimentos diretos externos.

Abstract: The argument developed in the paper, based on the food regime approach, is that the formation of the "Brazil-China soy-meat complex", from the early 2000s, represents a polycentric shift in global agri-food relations, driven by the interests of agribusiness corporations and food industries, as well as national states, in a South/East direction, which challenges the established power of the

1 O presente trabalho foi realizado com apoio da Coordenação de Aperfeiçoamento de Pessoal de Nível Superior-Brasil (Capes), Programa de Pós-Doutorado no Exterior, Processo n. 88881.171596/2018-01. Data de submissão: 31 de janeiro de 2018. Data de aceite: 28 de julho de 2018.

1. China Agricultural University, Beijing, China. E-mail: escher_fab@hotmail.com

2. Universidade Federal Rural do Rio de Janeiro (UFRRJ), Rio de Janeiro (RJ), Brasil. E-mail: jhn. wlknsn@gmail.com 
large North Atlantic transnational corporations. Based on the contemporary literature in agrarian political economy and in a combination of quantitative and qualitative data, we identify the origins, characteristics and dynamics of the Brazil-China soy-meat complex through a comparative and relational analysis. After a brief theoretical review, we examine the change in eating habits and class diets and the restructuring of meat (especially pork) and feed industries on the Chinese side, as an importing pole, and the commodities boom and the expansion in production, planted area and shipments of soybean on the Brazilian side, as an exporting pole. However, despite de importance of bilateral trade to the dynamics of the Brazil-China soy-meat complex, recently there has also been an increasing influx of Chinese investments in the Brazilian agribusiness. In the conclusions, beyond strict economic aspects, political aspects of the Brazil-China soy-meat complex are discussed.

Key-words: Brazil-China Soy-Meat complex, food regime, agribusiness, agricultural international trade, foreign direct investments.

Classificação JEL: O13, Q13, Q15, Q17, Q18.

\section{Introdução}

O desenvolvimento econômico e ascensão internacional da China como grande potência é sem dúvida o fato mais notável do capitalismo na era da globalização. Ao gerar impactos na divisão internacional do trabalho, na dinâmica global de acumulação de capital, nas finanças e na geopolítica, a China representa uma força de deslocamento dos Estados Unidos como centro de gravitação econômica e de hegemonia política no mundo hoje (Harvey, 2005; Arrighi, 2010; Kissinger, 2011). Na América Latina, a demanda chinesa e o seu efeito na alta dos preços das commodities energéticas, minerais e agrícolas têm sido o sustentáculo financeiro das trajetórias de crescimento econômico e da implementação de políticas sociais pelos governos de centro-esquerda nos países do continente (Armony \& Strauss, 2012; Sauer et al., 2018; Mckay et al., 2017; Vergara-Camus \& Kay, 2017). E particularmente no Brasil, os dados e a literatura indicam que o País experimenta um conjunto de impactos contraditórios associados ao assim chamado "efeito China" na sua economia ${ }^{2}$. Neste ensejo, o presente artigo visa contribuir

\footnotetext{
2 Ver Curado (2015), Jenkins (2015), Branco (2013), Honório \& Araújo (2014), Cunha et al. (2012), Cano (2012), Demeleumeester (2012), entre outros. Eles destacam três tipos de efeito: 1) impactos diretos: crescimento dos fluxos bilaterais de comércio, em que o Brasil exporta commodities agrícolas e minerais e importa máquinas, equipamentos e eletrônicos, com balanço comercial positivo, superávits em produtos primários e déficits em manufaturas e bens de capital; e crescimento dos fluxos e estoques de investimento, a maior parte em fusões e aquisições, principalmente nos setores de petróleo, gás, mineração, energia elétrica e agronegócios; 2) impactos
}

com este debate ao tratar especificamente do tema das relações agroalimentares entre Brasil e China. O seu objetivo precípuo é analisar as origens, características e dinâmicas do "complexo soja-carnes Brasil-China".

O conceito de "complexo grão-oleaginosa-pecuária", empregado no âmbito da abordagem dos "regimes alimentares", tem sido bastante referenciado na literatura internacional no campo de estudos agrários críticos. Porém, é surpreendentemente pouco utilizado no Brasil, onde prosperou até o final dos anos 1990 uma rica tradição teórico-analítica nos estudos agrários em torno do conceito similar de "complexo(s) agroindustrial(is)". $\mathrm{O}$ "complexo soja-carne Brasil-China" articula, pois, os dois países como "polos" comerciais. A China, como polo importador, passa por mudanças nos hábitos alimentares e dietas de classe da sua população rumo ao aumento do consumo de proteína animal e por reestruturações na produção pecuária e nas indústrias de carnes (principalmente suínos) e rações, devido à elevação da renda per capita, urbanização e afluência da nova classe média. E o Brasil, como polo importador,

indiretos: tendência altista nos termos de troca entre 2005 e 2012, com posterior queda e normalização em patamar mais baixo; apreciação cambial crônica devido a sua conta de capital aberta e desregulada; e competição em terceiros mercados, com perdas nas exportações de manufaturados para Estados Unidos (-12,87\%), União Europeia (-5,49\%) e América Latina $(-7,3 \%)$; e 3$)$ consequências estruturais, ligadas ao risco de "especialização regressiva" da economia brasileira, com os processos de "reprimarização" da pauta de exportação e de "desindustrialização precoce" na composição setorial da produção e do emprego. As relações econômicas Brasil-China, assim, parecem sugerir um novo padrão do tipo centro-periferia, já criticado pelos clássicos da Cepal. 
experimenta a expansão na área plantada, na quantidade produzida e nas exportações de soja em grãos, devido principalmente à demanda chinesa e seu efeito no nível de preços, pelo que se convencionou falar em "boom das commodities" (Wilkinson \& Wesz Junior, 2013; Schneider, 2014; Oliveira \& Schneider, 2016; Escher et al., 2018). No entanto, trabalhos recentes mostram que essa conexão vai além do comércio bilateral, uma vez que a interação entre as empresas e o estado chineses na realização de investimentos diretos externos (IDE) na soja e também em outras cadeias do agronegócio brasileiro (terras, insumos, açúcar, tabaco, celulose etc.) e suas infraestruturas relacionadas é crescente (Oliveira, 2015; Wilkinson et al., 2015; Escher et al., 2017).

Assim, pergunta-se como a noção de "complexo", que parecia datada na academia brasileira, ajuda a compreender as relações agroalimentares globais estabelecidas entre Brasil e China hoje? Quais são os fatores que impulsionam a formação do complexo soja-carne Brasil-China? Ao lado do notório peso do comércio bilateral, de que maneira a novidade dos crescentes investimentos chineses no agronegócio tem impactado a dinâmica recente do mercado de soja brasileiro? Além dos aspectos estritamente econômicos, que forças políticas estão mobilizadas na sustentação do complexo soja-carne Brasil-China? O argumento do artigo é que a formação do complexo soja-carne Brasil-China a partir dos anos 2000 tem forçado um deslocamento policêntrico ${ }^{3}$ na dinâmica do regime alimentar internacional, sob o impulso dos interesses das corporações do agronegócio e indústrias alimentares, bem como dos estados nacionais, numa direção Sul/Oriente, que desafia o poder estabelecido das corporações transnacionais do Atlântico Norte, mas tampouco está isento de contradições.

Importante pontuar dois esclarecimentos metodológicos. De um ponto de vista mais amplo, a perspectiva metodológica que orienta o trabalho pode ser caracterizada ao mesmo tempo como comparativa e relacional. Comparativa porque busca identificar paralelos, traçando semelhanças gerais e diferenças cruciais nas trajetórias dos sistemas agroalimentares de Brasil e China de modo a contextualizar a emergência

3 Neste texto, concentramo-nos apenas nestes dois países, reconhecendo, contudo, que uma análise completa deste deslocamento policêntrico certamente teria que incluir os demais "Brics" (Rússia, Índia e África do Sul), bem como outros países de renda média (MICs na sigla em inglês) (ver Cousins et al., 2018). do complexo soja-carne como um fenômeno histórico constitutivo do regime alimentar internacional não restrito aos determinantes domésticos de cada país. Relacional porque busca avaliar os fatores impulsionadores e as implicações decorrentes das relações diretas de comércio e investimento entre os dois países nos seus respectivos sistemas agroalimentares. E de um ponto de vista metodológico mais estrito, o trabalho está apoiado em resultados de pesquisas prévias dos autores e um conjunto de novos dados. As fontes secundárias abrangem bases de dados quantitativas, como as estatísticas oficiais brasileiras, chinesas e internacionais, e qualitativas, como notícias divulgadas pela imprensa de negócios brasileira, chinesa e internacional, bem como uma ampla revisão da literatura relevante. Ademais, a análise também utiliza fontes primárias de dados qualitativos coletados em trabalho de campo no estado de Mato Grosso (principal locus da produção de soja e dos investimentos chineses no agro brasileiro), como entrevistas e conversas informais com representantes de corporações transnacionais, empresários locais e grandes produtores.

O artigo está estruturado em seis seções, sendo a primeira a introdução. A segunda seção apresenta uma discussão sintética do referencial teórico e dos conceitos chave que fundamentam a análise. A terceira e a quarta seções tratam respectivamente dos principais fatores que impulsionam a formação do complexo soja-carne no lado chinês, como polo importador, e no lado brasileiro, como polo exportador. A quinta seção mostra que a dinâmica recente do complexo soja-carne Brasil-China vai além das relações comerciais, ao analisar as tendências dos investimentos chineses no agronegócio brasileiro. E na última seção, as conclusões destacam as contradições do complexo soja-carne Brasil-China no campo político.

\section{Regimes alimentares, complexos agroindustriais e outras complexidades teóricas}

O tema agroalimentar é, com perdão do trocadilho, complexo. Complexo tanto no sentido de "complicado", "confuso", que não é simples, de difícil compreensão, como de "composto", "multifacetado", que abarca e compreende um conjunto de elementos ou aspectos distintos que guardam nexo entre si, com relações de 
interdependência. A presente seção visa, portanto, esclarecer o conteúdo e o sentido heurístico da noção de "complexo" utilizada nesse trabalho. O quadro analítico geral dentro do qual o conceito se insere é informado pela abordagem dos regimes alimentares. O debate brasileiro dos anos 1980-1990 sobre "complexos agroindustriais" é revisitado numa leitura crítica, mas que destaca a sua importante contribuição. Esta discussão teórico-metodológica fundamenta a elaboração do conceito de "complexo soja-carne Brasil-China" operacionalizado nas seções seguintes.

A noção de "sistema agroalimentar" é amplamente utilizada na literatura. Ela faz referência a um conjunto de atores e instituições, tecnologias e processos envolvidos na produção, circulação e consumo agroalimentar de uma economia, abrangendo os distintos elos e nós das suas cadeias e redes de mercadorias, desde o produtor primário até o consumidor final. Isso passa pelas indústrias de insumos e máquinas, o transporte, a agroindústria processadora, o comércio atacadista e varejista, os mercados local, doméstico e externo, o estado e suas políticas públicas, e as interrelações entre estes diversos componentes. O modo de explicar e interpretar estas interrelações, contudo, depende da teoria desposada.

A abordagem dos "regimes alimentares" (Food Regimes), cujo artigo de Friedmann \& Mcmichael (1989) é o marco inaugural, é uma das principais referências nos estudos rurais e agroalimentares desde os anos 1980, com renovado interesse atualmente ${ }^{4}$. A noção de regime alimentar aponta para uma lógica política e econômica na dinâmica da agricultura e da alimentação na evolução do capitalismo. Essa lógica se expressa por meio das ações, práticas e estratégias de certos atores (grandes empresários, investidores e proprietários fundiários, agricultores e consumidores) e instituições (corporações, bancos, burocracias estatais, grupos de interesse, agências multilaterais e movimentos sociais) do sistema agroalimentar e se reflete nos conflitos de poder e disputas por hegemonia, que, por sua vez, direcionam os modos de ordenamento das relações de produção, circulação e consumo em escala global. "A 'clássica' definição de regimes alimentares inclui constelações de relações de classe, especialização geográfica e poder

4 Ver Schneider et al. (2016) para uma introdução geral, McMichael (2009), para um balanço, e Bernstein (2016), McMichael (2016), Friedmann (2016) e Wilkinson \& Goodman (2015), para uma avaliação crítica. interestatal, articulando 'relações internacionais de produção e consumo alimentar' a 'períodos de acumulação de capital'" (Friedmann, 2009, p.335). [Isto envolve] uma constelação específica de governos, corporações, organizações coletivas e indivíduos, que permite uma acumulação de capital baseada um uma definição compartilhada dos propósitos dos atores-chave, enquanto os outros são marginalizados (Friedmann, 2005, p.229).

Com base nesta formulação teórica e numa abrangente análise histórica, os autores elaboram uma periodização da dinâmica da agricultura e da alimentação na evolução do capitalismo, identificando três épocas dos "regimes alimentares internacionais", conforme sistematizado no Quadro 1.

Não há consenso acerca do caráter do terceiro regime alimentar, pois dois elementos essenciais do primeiro e do segundo regimes - a ascensão de uma nova potência hegemônica e da sua moeda como padrão do sistema financeiro internacional - não se verificam plenamente no período contemporâneo. Primeiro, faltam sinais claros de uma subversão definitiva da hegemonia norte-americana, embora a ascensão da China seja fato notável no desenho de uma nova ordem mundial. Segundo, o sistema financeiro internacional de câmbio flexível governado pelo dólar vive um momento de instabilidade e incertezas desde a crise de 2008, mas nenhuma alternativa imediatamente crível se apresenta. Não obstante, o ano de 1995 parece demarcar a formação de um novo regime, com o estabelecimento da Organização Mundial do Comércio (WTO) e do Acordo sobre Agricultura $(A o A)$ institucionalizando a liberalização dos mercados nacionais e restringindo os direitos dos estados de regular a agricultura e a alimentação. Sob a ideologia neoliberal da globalização e do estado mínimo, ocorre uma crescente financeirização da riqueza (fundos de investimento, instrumentos de hedge, derivativos cambiais, mercados futuros), tanto com atores financeiros atuando nos ramos de agricultura, alimentação e mercado de terras, quanto com empresas agroalimentares atuando em atividades e operações com instrumentos financeiros. As corporações transnacionais passam, então, a dominar não só as indústrias a montante (máquinas, biotecnologias e agroquímicos) e a jusante (processamento de alimentos) da agricultura, mas também os grandes canais de distribuição do comércio varejista (revolução dos supermercados), pelo que lhes cabe a alcunha de "impérios alimentares". E a onda recente de 
Quadro 1. Síntese dos regimes alimentares internacionais.

\begin{tabular}{|l|l|l|l|}
\hline \multicolumn{1}{|c|}{ Características } & \multicolumn{1}{|c|}{$\mathbf{1}^{\circ}$ Regime Alimentar } & \multicolumn{1}{c|}{$\mathbf{2}^{\circ}$ Regime Alimentar } & \multicolumn{1}{c|}{$\mathbf{3}^{\circ}$ Regime Alimentar } \\
\hline Nome & Colonial-Diaspórico & Mercantil-Industrial & Corporativo-Ambiental \\
\hline Período de Duração & $1870-1914 / 30$ & $1945-1973 / 85$ & $1995 / 2001$-hoje (?) \\
\hline Potência Hegemônica & Grã-Bretanha & Estados Unidos & Eixo China/EUA (?) \\
\hline Estrutura de Governança & Impérios Coloniais & Estados Nacionais & Corporações Transnacionais \\
\hline Ideologias Dominantes & Liberalismo-Colonialismo & Desenvolvimentismo- Anticomunismo & Neoliberalismo- Globalização \\
\hline Sistema Monetário & Padrão Ouro-Libra & Dólar-Ouro (Bretton Woods) & Dólar-Flexível (Pós-Bretton Woods) \\
\hline Paradigma Tecnológico & Tradicional, artesanal & Mecânica e química & $\begin{array}{l}\text { Biotecnologias, nanotecnologias, } \\
\text { tecnologias informação e comunicação }\end{array}$ \\
\hline Principais tipos de produtos & $\begin{array}{l}\text { Alimentos básicos para } \\
\text { preparação caseira }\end{array}$ & $\begin{array}{l}\text { Alimentos básicos e processados } \\
\text { para preparação caseira e refeições } \\
\text { fora de casa }\end{array}$ & $\begin{array}{l}\text { Alimentos básicos e processados para } \\
\text { preparação caseira e refeições fora } \\
\text { de casa, conveniência e flexibilidade }\end{array}$ \\
\hline Identificadores de qualidade & $\begin{array}{l}\text { Produtos sem marca e } \\
\text { sem diferenciação }\end{array}$ & Produtos diferenciados por marca & $\begin{array}{l}\text { Produtos diferenciados por marca, } \\
\text { certificações, marcas próprias dos } \\
\text { supermercados, marcas genéricas }\end{array}$ \\
\hline Movimentos Contendores & Trabalhadores & Agricultores & Consumidores \\
\hline
\end{tabular}

Fonte: Schneider et al. (2016).

investimentos massivos na compra de largas extensões de terra por estrangeiros nos países em desenvolvimento (global land grabbing) e em fusões e aquisições para a concentração e centralização de capital pelas grandes corporações do agronegócio no rescaldo do "boom das commodities e flex crops" também constitui parte decisiva da reestruturação do atual regime alimentar (McMichael, 2013; Ploeg, 2010; Clapp, 2014, 2017; Isakson, 2014; Borras et al., 2016; Borras \& Franco, 2012).

A noção de "complexos transnacionais de mercadorias agroalimentares" vem à luz em um trabalho de Friedmann (1991), no qual ela analisa o papel da agricultura de exportação desde a transição do primeiro para o segundo regime alimentar. Segundo a autora, no contexto de mudanças na divisão internacional do trabalho do pós-guerra, o advento dos padrões "fordistas" de produção e consumo de massa nos países desenvolvidos e a difusão do modelo de agricultura industrial moderna pelo paradigma tecnológico da "revolução verde" nos países em desenvolvimento consolidaram quatro grandes complexos agroalimentares em nível global: o complexo trigo (e milho), o de alimentos duráveis (oleaginosas), o pecuária/ração, e o de produtos tropicais (café, banana etc.). McMichael (2009) também contribuiu para o estudo dos complexos agroalimentares ao analisar as relações entre diversos países no âmbito do comércio internacional, articulados enquanto "polos de importação" e "polos de exportação" de um conjunto de commodities, destacando a ascensão das corporações do agronegócio como atores dominantes nos diversos ramos relacionados.
Ainda, a contribuição de Weis (2013) sobre a formação histórica e as contradições biofísicas do "complexo agroindustrial grãos-oleaginosas-pecuária" é fundamental.

O complexo industrial grãos-oleaginosas-pecuária envolve uma profunda reconfiguração dos imperativos de organização histórica da agricultura com base na diversidade funcional, na complementaridade e em ciclos de material relativamente fechados. A mecanização e a busca de economias de escala demoliram esses imperativos e substituíram [pela] simplificação biológica e [a] padronização. A expansão e industrialização da produção de grãos e oleaginosas e da produção pecuária têm se reforçado mutuamente. Em outras palavras, o aumento das populações de gado não é apenas sobre o aumento das oportunidades de valor agregado nas carnes, leite e ovos, mas também sobre a transformação dos excedentes estruturais de grãos e oleaginosas de um moinho deflacionário em uma fonte crescente de ganhos de baixa margem para agricultores de larga escala, processadores e traders. O complexo industrial grãos-oleaginosas-pecuária é o sistema dominante de agricultura em todo o mundo temperado, e se espalha para partes significativas dos trópicos. Suas paisagens podem ser comparadas a ilhas de gado concentrado em mares de monoculturas de cereais e oleaginosas. [Desarticuladas] dos seus [ambientes circundantes, [essas] ilhas de gado confinado e mares de monoculturas são então rearticuladas por pesados fluxos de [ração] circulando através dos animais. Esta desarticulação e rearticulação é mediada por uma série de tecnologias, insumos, [mercados] e grandes corporações, e depende 
do uso insustentável de recursos não renováveis e da externalização de custos sociais e ambientais (Weis, 2013).

Após essa sintética digressão sobre o conceito de "complexo" na abordagem dos regimes alimentares internacionais, cabe revisitar esta noção tal como foi trabalhada na literatura econômica brasileira entre meados dos anos 1980 e final dos 1990. Grosso modo, é razoável distinguir entre duas concepções diversas: uma que empregava o conceito de "complexo agroindustrial - CAI", no singular; e outra que empregava o conceito de "complexos agroindustriais - CAIs", no plural. Ambas as concepções compartilhavam importantes aspectos. Ambas tinham maior proximidade com as correntes heterodoxas (Marx, Keynes) do que ortodoxas (Neoclássica) da teoria econômica, que usualmente viam a agricultura numa perspectiva setorial, separada do resto da economia; buscavam interpretar as mudanças decorrentes da "modernização conservadora" da agricultura brasileira a partir de 1964, sob a égide do regime militar; e enfatizavam que este processo ia além da transformação da base técnica da produção agropecuária, pois envolvia a integração técnico-produtiva intersetorial entre a agricultura e os ramos industriais à montante e à jusante, a integração dos capitais sob o comando do capital financeiro e as políticas macroeconômicas e creditícias do estado. Mas também havia diferenças importantes entre elas.

A primeira concepção, representada pelos trabalhos de Müller (1981, 1990), usava a noção de "complexo agroindustrial" (CAI) no sentido de um conjunto de atividades inter-relacionadas e agregadas intersetorialmente a partir de um recorte estático na matriz insumo-produto. Metodologicamente, o CAI guardava proximidade com a noção de "agribusiness", tal qual formulada por Davis \& Goldberg (1957). Mas teoricamente utilizava um vocabulário marxista, destacando que mais do que a simples integração intersetorial da agricultura às cadeias produtivas, o objetivo da fusão dos capitais é a busca da taxa média de lucro dos conglomerados, cuja distribuição seria planificada pela política do estado, que supostamente paira "acima dos interesses" dos capitalistas particulares. Apesar do seu pioneirismo em superar a visão setorial tradicional da economia ortodoxa e do rigor metodológico no tratamento dos dados estatísticos, essa concepção de CAI sofreu um conjunto de críticas. Para Silva (1998), ela superestima a capacidade do estado planejar ex ante a distribuição dos lucros e regular a concorrência entre os capitais privados; e recorta um nível muito agregado, em que os agentes tomadores de decisão são, na prática, as empresas ou os grupos, sendo pouco operativa como unidade de análise. E para Goodman et al. (1986), ela supõe implicitamente que os capitais são homogêneos e livres de conflitos e contradições entre si, quando na lógica da concorrência o que ocorre é exatamente o oposto; e que há um processo de trabalho unificado na produção capitalista na agricultura e uma divisão estática dos limites entre agricultura e indústria, quando na verdade essa unidade não se verifica e estes limites estão em constante mudança, determinados pela dinâmica das inovações tecnológicas através das tendências de "apropriação" à montante e de "substituição" a jusante da produção agropecuária.

Enquanto a segunda concepção, representada pelos trabalhos de Silva (1998) e de Kageyama (1987), usava a noção de "complexos agroindustriais" (CAIs) no sentido de relações multideterminadas de encadeamento, coordenação e controle entre vários elementos, etapas, atores e processos que compõem as cadeias produtivas agroindustriais. Eles também usavam o instrumental quantitativo da matriz insumo-produto; porém, a sua metodologia privilegiava aspectos qualitativos na delimitação dos seus componentes, adquirindo um caráter histórico e dinâmico. Teoricamente, com base em Rangel (1962) e Lenin (1983), os autores propunham-se a explicar a "passagem do complexo rural aos complexos agroindustriais" no Brasil. Os complexos rurais (um mosaico de atividades agrícolas e manufatureiras artesanais interligadas e internalizadas dentro das fazendas coloniais) entraram em declínio com o fim da escravidão e foram se rompendo com a ampliação da divisão social do trabalho e a expansão do mercado interno, impulsionado pelo processo de industrialização por substituição de importações que caracterizou o desenvolvimento do capitalismo no Brasil. Com o amadurecimento da estrutura industrial nos anos 1960 e 1970 é constituído o D1 (departamento de meios de produção) para a agricultura (insumos e máquinas), que substitui o D2 (departamento de bens de consumo) como eixo dinâmico da acumulação de capital. Com isso, altera-se a base técnica da agricultura modernizada, reconstitui-se a agroindústria processadora e cria-se uma nova gama de serviços especializados em torno das cadeias de valor sobre bases propriamente capitalistas. Formam-se aí os complexos agroindustriais, interconectados entre os ramos de demanda final (D2) e os ramos de meios de produção (D1) para determinados produtos de origem agropecuária (carnes-ração-óleos 
vegetais, tabaco, sucroalcooleiro etc.). Todos montados sobre uma dinâmica endógena, com grupos de interesse organizados e associações de representação política responsáveis pela sua legitimação social, levantamento de demandas específicas e lobby junto ao estado, que, como árbitro, passa a dirigir-se aos complexos como instâncias de mediação na orquestração de interesses privados e públicos e na coordenação das ações coletivas.

Outras abordagens têm sido usadas para analisar as relações agroalimentares em nível global, como as "cadeias globais de valor" e as "redes globais de produção" (Wilkinson, 2006). A abordagem das "assemblages" também busca fazer isso através de uma perspectiva geográfico-antropológica (Hollander, 2010), a exemplo da tese de Oliveira (2017), que estuda os IDEs chineses no agronegócio brasileiro. Contudo, pelo fenômeno estudado e o tipo de dados que dispomos, o aporte teórico-metodológico exposto parece adequado para operacionalizar frutiferamente o conceito de "complexo soja-carne Brasil-China". A construção do conceito parte do nível mais abstrato e geral do regime alimentar internacional para os níveis mais desagregados e específicos dos complexos transnacionais de mercadorias, com seus polos de importação e exportação e de envio e recebimento de investimentos, do complexo grãos-carnes-oleaginosas, com suas ilhas de pecuária concentrada e mares de monocultura, e dos complexos agroindustriais, com suas dinâmicas endógenas de acumulação de capital e de orquestração e coordenação de interesses. Assim, a análise que segue pretende identificar e compreender as forças econômicas, sociais e políticas que impulsionam a formação do complexo soja-carne Brasil-China, com foco nos atores e instituições envolvidos, nas estratégias perseguidas, nas dinâmicas engendradas e nas consequências resultantes.

\section{China: dietas de classe, reestruturação das indústrias de carnes e rações e desafios da política de segurança alimentar}

A China é uma civilização historicamente agrícola, onde a comida é e sempre foi um traço identitário da sua cultura. Mas apesar das especificidades nacionais, variações regionais e diferenças com o Ocidente, a sua experiência de desenvolvimento econômico nas últimas décadas vem sendo acompanhada por um processo secular chamado de "transição nutricional", o qual impulsiona transformações nos hábitos alimentares e dietas de classe da população.

O velho padrão chinês de consumo alimentar de 8:1:1, oito partes de grãos, uma parte de carnes-peixes e uma parte de vegetais-frutas [...], tem mudado rapidamente para um padrão 4:3:3, de quatro partes de grãos, três partes de carnes-peixes (e ovos e leite), e três partes de vegetais-frutas. A transformação já está bem avançada e, se a renda continuar a subir (embora a uma taxa reduzida em comparação com os últimos 30 anos), ela deve ser concluída durante a década de 2015 a 2025. Isso trará os padrões de consumo alimentar chineses muito mais próximos aos dos países desenvolvidos. (Huang, 2011, p.4).

A renda per capita da China (em paridade de poder de compra PPP) cresceu de U\$ 302 em 1980 para US\$ 1.227 em 1992, US\$ 3.804 em 2003, US\$ 9.012 in 2010 e U\$ 12.879 em 2014 (International Monetary Fund, 2015). Sua taxa de urbanização, de 18\% em 1980, excedeu os 50\% em 2010 (China Statistical Yearbook, 2015). O número de pessoas abaixo da linha da pobreza de US\$1.25 por dia (PPP), decresceu de 63,8\% da população em 1992 para $28,4 \%$ em 2002 e 11,8\% em 2009, chegando a menos de 1\% em 2019 (World Bank, 2019). Entre 1980 e 2010, o gasto domiciliar per capita com comida (em preços nominais) cresceu 22 vezes nas áreas rurais e 15 vezes nas áreas urbanas, e sua fatia no gasto total decresceu de $68 \%$ para $41 \%$ nas áreas rurais e de $57 \%$ para $36 \%$ nas áreas urbanas (Garnett \& Wilkes, 2014). A elevação da renda, a urbanização e a nova classe média afluente ao mercado de consumo são os determinantes das rápidas transformações da economia e da sociedade iniciadas com a política de reformas e abertura. E os novos hábitos baseados no consumo de carne jogam um importante papel enquanto práticas de distinção e marcador social na definição das identidades de classe dos consumidores. Desde meados dos anos 1980 o consumo per capita de carne na China quadruplicou, chegando a $61 \mathrm{~kg}$ de carne por pessoa em 2010. Embora seja uma média baixa quando comparada a dos Estados Unidos (120 kg), ela é bastante razoável em comparação com a média do Brasil (73kg) e está bem acima da média mundial $(42 \mathrm{~kg})$ 
(Schneider, 2014) ${ }^{5}$. A China produz e consome mais de $50 \%$ da carne de porco do mundo, o que representa $39 \mathrm{~kg}$ per capita, com estimativas de chegar a $50 \mathrm{~kg}$ em 2025 (Wilkinson et al., 2015). É sintomático disso, portanto, que "em mandarim a palavra geral para carne ( $r o u)$ se refere a porco, e o caractere chinês para lar e família, 家(jia), tenha sido criado há mais de 3.500 anos, adicionando o radical teto ao radical porco, ou mais figurativamente, colocando um teto sobre a cabeça do porco" . (Schneider \& Sharma, 2014, p.21).

Essas mudanças na demanda induziram transformações na produção pecuária, reestruturações na indústria da carne e crescentes importações de soja como matéria-prima da fabricação de rações na China. Até 1985, produtores camponeses produziam pelo menos 95\% de carne de porco do país. No entanto, em 2009 o número de unidades familiares rurais que produziam porcos na China como um todo caiu $50 \%$ (com variações regionais). Essa nova realidade é acompanhada de um processo de diferenciação dos produtores: os produtores de quintal (1 a 10 suínos/ano) foram responsáveis por $27 \%$ da produção nacional de suínos; os produtores familiares especializados (50 a 500 suínos/ano), por $51 \%$; e os produtores comerciais de grande escala (> 500 suínos/ano), por $22 \%$. Como tendência dominam a especialização, o aumento da escala e a concentração da produção, com criação de barreiras à entrada, seleção e exclusão de pequenos produtores camponeses. A maioria das operações em escala comercial é hoje realizada por produtores e empresas domésticas, mas é comum a presença de companhias estrangeiras atuando em ramos de maior nível tecnológico a montante (genética, rações, equipamentos). As instalações e métodos de produção caracterizam-se como "operações de alimentação de animais confinados / concentrados (CAFOs)", localizadas principalmente nas costas leste e sudeste, onde se concentram as maiores plantas de abate e processamento, e também na região centro-oeste, particularmente a província de Sichuan (Schneider \& Sharma, 2014).

\footnotetext{
5 Segundo estimativas oficiais da FAO, em 2017, o consumo per capita de carne no país chegou a $88 \mathrm{~kg}$, sendo que a carne de porco chegou a $31 \mathrm{~kg}$ (Food and Agriculture Organization Statistics Division, 2019). Os autores acima referidos, entretanto, utilizam estimativas de outras instituições não oficiais como fonte, as quais apontam cifras ainda maiores.

6 Estes dados sobre diferenciação de produtores até 2009, citados por Schneider \& Sharma (2014), baseiam-se em um relatório do Rabobank, publicado em 2012. Não existem informações mais atualizadas a respeito.
}

Apesar das lógicas e práticas comuns ao agronegócio de qualquer lugar, a propriedade e as operações na indústria de carne chinesa são essencialmente domésticas, com base no modelo de "empresas cabeça de dragão" (DHEs na sigla em inglês) e "contratos empresa e produtor" (gongsi + nonghu em chinês). DHEs são as firmas líderes do agronegócio que, apoiadas por grossos créditos e subsídios governamentais, coordenam uma série de etapas das cadeias de valor (criação e reprodução de leitões, fornecimento de ração e insumos, processamento, distribuição e venda da carne), por meio de estratégias combinadas de integração vertical e agricultura de contrato. Segundo estatísticas oficiais (superestimadas, mas indicadoras de uma realidade notória), as DHEs integram operações de cerca de $70 \%$ da produção pecuária (porcos e frangos), $80 \%$ da aquicultura e $60 \%$ da área cultivada. Tal processo de integração avançou sobremaneira após a recorrência da gripe asiática. Em 2011, oito das 10 maiores firmas de abate de suínos, nove das 10 maiores firmas de processamento e embalagem, oito das 10 maiores firmas de distribuição e seis das 10 maiores firmas de criação e reprodução de leitões eram DHEs. Shanghui, que após a aquisição da norte-americana Smithfield em 2013 mudou de nome WH Group e tornou-se a maior processadora e distribuidora de carne suína do mundo, junto a Jinluo e Yurun, são as três maiores DHEs no ramo. Elas realizam cerca de $70 \%$ das vendas das 10 maiores processadoras e distribuidoras (Schneider \& Sharma, 2014).

Após a adesão da China à OMC em 2001, o estado reduziu impostos e tarifas e liberalizou seletivamente a soja e outras oleaginosas, basicamente pelo seu papel na indústria das carnes ${ }^{7}$. Tanto que em 2014 as importações de soja da China contabilizam $64 \%$ do comércio global e $85 \%$ do seu consumo interno, sendo que três países respondem por $97 \%$ das exportações de soja para a China (Brasil com 45\%, EUA com 39\% e Argentina com 13\%). Do total da soja importada, são esmagados $85 \%$ para farelo (produto principal) e óleo (subproduto) e os $15 \%$ restantes para outros derivados (usos industriais) (Oliveira \& Schneider, 2016). A indústria de rações também é controlada por DHEs. No $12^{\circ}$ Plano Quinquenal foi estabelecida a meta de ter 50 fábricas produzindo $50 \%$

\footnotetext{
7 Alimentos derivados de soja seguem comuns nas dietas e na culinária chinesa, mas provêm basicamente de produção doméstica não transgênica (NOGM). Enquanto a soja consumida cada vez mais como carne de porco ou frango industrial, bem como óleo de cozinha, em sua maioria é OGM proveniente de importações.
} 
da ração consumida no país até 2015. Em 2010, segundo dados oficiais, 16 firmas estavam produzindo $33 \%$ da ração consumida na China. E especialistas do setor estimam que, em 2014, as 10 maiores firmas já estariam produzindo $50 \%$ da ração. Não é de se admirar que na lista das 100 maiores empresas de ração do mundo, classificadas por volume, 29 sejam chinesas, sendo que, destas, oito estão entre as top 20 (Sharma, 2014).

Todo esse processo esteve permeado por conflitos e disputas de interesses entre os produtores de soja chineses, indústrias do esmagamento domésticas, trabalhadores da agroindústria e as grandes traders globais (Yan et al., 2016). A China começou a importar farelo em meados dos anos 1990, mas devido a reclamações em relação ao achatamento da margem de lucro e as perdas no emprego e no valor agregado local, logo voltou-se à importação de grãos. A China detém $28 \%$ da capacidade de esmagamento de soja no mundo hoje. Em 2000, quase toda essa capacidade era controlada por firmas domésticas. Porém, após a "crise da soja de 2004", quando esmagadores e refinarias chinesas deram default em contratos com os EUA devido à quebra de preços ocorrida naquele ano e foram forçadas à falência, as grandes empresas de trading ocidentais ABCD (ADM, Bunge, Cargill, Louis Dreyfus) e asiáticas NOW (Noble, Olam, Wilmar) aproveitaram a oportunidade para tomar $70 \%$ do controle. Em 2009, elas controlavam $80 \%$ do esmagamento e $60 \%$ do refino da soja na China. Contudo, motivado pelo alarido doméstico, em 2007 o governo lançou políticas para conter o avanço das firmas estrangeiras e apoiar a retomada da indústria nacional no setor. Resulta que a partir do final da década de 2000 as firmas chinesas voltaram a controlar $72 \%$ da capacidade de esmagamento, embora haja muita capacidade ociosa e as firmas estrangeiras respondam por cerca de $60 \%$ do esmagamento realmente em operação (Oliveira \& Schneider, 2016; Sharma, 2014).

Os efeitos destas mudanças nos hábitos de consumo e nas cadeias de valor agropecuárias aparecem refletidos na política alimentar chinesa. A principal tem a ver com a redução da fome. Ainda que siga num nível moderadamente alto, o percentual de pessoas com subnutrição crônica na China passou de 23,9\% no biênio de 1990-1992 para 16,1\% em 2000-2002 e para 10,6\% em 2012-2014 (Food and Agriculture Organization, 2014). No entanto, num livro com o provocativo título "Quem alimentará a China?", Brown (1995) questionava a habilidade do país em prover alimentação básica à sua população em 2020 sem precisar recorrer à compra de grandes quantidades de grãos no mercado agrícola internacional, gerando uma pressão altista nos preços globais dos alimentos. Sobre isso, Xu et al. (2014) explicam que o governo chinês, usando estatísticas oficiais, afirma que a produção de grãos da China diminuiu de 512 para 431 milhões de toneladas entre 1998 e 2003, mas que desde 2004 o país tem conseguido "dez anos de crescimento consecutivo" na produção de grãos, atingindo 602 milhões de toneladas em 2013, quase 40\% acima do nível de 2003. Entretanto, para eles os números do governo estão superestimados e, através de cálculos alternativos, afirmam que desde 2008 há uma discrepância entre a estatística oficial e a sua estimativa que chega a $22 \%$ em 2012, inferindo que, neste ano, a produção seria de 100 milhões de toneladas abaixo do cálculo do governo. E questionam que no curto prazo as crescentes importações de soja e milho para ração acentuam a dificuldade de a produção doméstica alcançar a demanda e que no longo prazo a oferta de cereais da China pode ser ainda mais prejudicada pelas restrições de recursos de terra e água, bem como pela degradação ambiental que segue muito alta.

Mcbeth \& Mcbeth (2010) ratificam que os problemas ambientais e de segurança alimentar são reconhecidos pela elite, que os cidadãos os incluem na avaliação do desempenho do governo e que até agora a China tem conseguido alimentar a sua imensa população. De modo que esta não é uma preocupação imediata, mas que já no médio prazo será. Assim, se não for enfrentada logo, constituirá um perigo a estabilidade social e política do país. O ponto a salientar é que a "questão agroalimentar" da China é mais complexa do que uma simples questão quantitativa. Zhou (2010) demonstra que a China tem mantido reservas de grãos bastante acima do seu consumo anual, que a diversificação na oferta de outros produtos (carnes, leite, ovos, frutas, vegetais, aquáticos) é marcante e que a melhoria no acesso aos alimentos é significativa. E daí infere que a ingestão média de energia da população chinesa alcança o requerido, que a ingestão de proteína é adequada, mas nas áreas rurais ainda é baixa e precisa ser melhorada, e que a ingestão de gorduras alcança o requerido, mas nas áreas urbanas e rurais mais ricas têm tornado-se excessiva. Com efeito, desequilíbrios nutricionais começam a emergir (aumento nos índices de sobrepeso e obesidade e de doenças crônicas não transmissíveis, maior nível de desperdício de alimentos e 
recorrentes escândalos de sanidade alimentar). Sem falar dos problemas ambientais em grande escala, da persistência da pobreza e do aumento das desigualdades sociais e regionais que minam a estabilidade social, bem como da falta de transparência com a gestão das reservas e estoques públicos de grãos.

Tudo isso faz crer que há uma contradição entre as narrativas e discursos oficiais do governo sobre segurança alimentar e as práticas de política pública realmente implementadas na China. No seu âmago está uma questão conceitual sutil, mas de importância crucial. O termo "segurança alimentar" (shipin fangyu anquan), no sentido usado no Ocidente segundo a definição da FAO, apenas recentemente começou a aparecer nos escritos acadêmicos e reportes oficiais chineses, basicamente em documentos que explicam as políticas da ONU ou voltados ao público estrangeiro. Já o termo "segurança dos alimentos" (shipin anquan), no sentido de sanidade, este sim é utilizado na regulação estatal, nos meios de comunicação e no debate público na esteira dos escândalos alimentares recentes. Mas o termo de fato usado e praticado no campo das políticas públicas de alimentação é "segurança de grãos" ou "autossuficiência de cereais" (liangshi anquan) (Christiansen, 2009; Zhou, 2010). Isso significa aderir a um patamar de no mínimo 95\% de produção doméstica de grãos, sendo arroz, trigo e milho os três cereais considerados "cultivos estratégicos" que compõem a cesta de alimentos básicos para o consumo direto da população. Desde a entrada da China na OMC, em 2001, a soja e outras oleaginosas foram excluídas da cesta básica de cereais e liberalizadas, de modo que hoje o país é dependente do comércio internacional para suprir sua demanda. O governo mantém o milho como um cultivo estratégico, mas como é um insumo importante na fabricação de rações e sua produção doméstica é com base em sementes não transgênicas a custos maiores do que em países como Estados Unidos, Brasil e Argentina, muitos têm afirmado que num futuro próximo a China deve depender cada vez mais fortemente do mercado internacional para garantir também a oferta de milho diante da sua crescente demanda (Sharma, 2014).

A questão crítica é que esta confusão ou ambiguidade terminológica ofusca a mudança crucial nas dietas da população chinesa, com o crescimento do consumo de carnes e o declínio do consumo de grãos. Entre estimativas pessimistas e otimistas, a China possui de 121 a 137 milhões de hectares de terra arável, 2.818 bilhões de metros cúbicos anuais de fluxos de água doce e uma população de quase 1.4 bilhão. Daí o slogan oficial do "Desafio 21/9" para a segurança alimentar (21\% da população, 9\% da terra arável e 7\% da água doce do mundo) (Mcbeth \& Mcbeth, 2010). Assim, quando o governo exulta o seu sucesso com chavões do tipo "a China alimenta $21 \%$ da população mundial com $9 \%$ da terra agrícola, fazendo grande contribuição à segurança alimentar" e "nós alimentaremos a nós mesmos!" em resposta a "quem alimentará a China?", está dizendo apenas que atinge o patamar de $95 \%$ de autossuficiência de grãos. Mas esconde que depende de importações para 4/ 5 da soja e cada vez mais do milho que consome para alimentar a indústria de rações, que, por sua vez, vai para produzir a carne, que já representa 3/10 da dieta média do consumidor chinês (Huang, 2011).

Na China se critica o egoísmo e a hipocrisia dos ocidentais, que já comem muita carne e não querem que os chineses façam o mesmo, alegando que isso representa uma "ameaça à sustentabilidade". Porém, nos últimos anos até mesmo o governo vem demonstrando consciência do problema, por razões ambientais (poluição da água e emissões de CO2), sociais (desigualdade de consumo entre as classes) e de saúde (aumento da obesidade e doenças associadas), e que é necessária uma política para reduzir o crescimento do consumo de carne no país ${ }^{8}$. Mesmo assim, as pessoas querem e desejam comer mais carne, o que lhes parece um progresso contra um passado de escassez; e o governo também é consciente de que garantir a "modernização das dietas" da população é importante para sua própria legitimidade e confiança pública. Portanto, nos próximos anos o país enfrentará o desafio de, por um lado, continuar a prover mais alimentação e de melhor qualidade para a parcela da população que ainda carece disso e, por outro lado, simultaneamente abordar os efeitos dos excessos e desequilíbrios alimentares da outra parte da população - sendo que o problema da "carnificação das dietas" está no centro desse duplo desafio (Garnett \& Wilkes, 2014; Schneider, 2014).

8 Em 2016, o governo chinês lançou um plano com novas diretrizes dietéticas, visando reduzir o crescimento do consumo de carne em $50 \%$ até 2030 , o que, por sua vez, poderia reduzir as emissões de gases de efeito estufa em 1 bilhão de toneladas e diminuir os crescentes problemas do país com obesidade e diabetes. 


\section{Brasil: boom das commodities, expansão da produção, da área plantada e das exportações de soja, e corrida ao mercado de terras}

Entre meados dos anos 1980 e início dos 1990, o processo de "modernização da agricultura" brasileira instaurado durante os governos militares degringolou. Após a crise cambial de 1999, o governo FHC promoveu uma política de "relançamento do agronegócio" para manter a conta de transações correntes do balanço de pagamentos. E por meados dos 2000, sob os governos do PT, consolidou-se um padrão de acumulação de capital alicerçado no boom das commodities e na valorização do preço da terra, sustentado na aliança entre a grande propriedade fundiária e os complexos agroindustriais internacionalizados e afiançado pela política macroeconômica e creditícia do estado (Delgado, 2012).

Neste ínterim, explode a expansão da área plantada, da quantidade produzida, da produtividade e das exportações de soja no Brasil, a contraparte brasileira na formação do "complexo soja-carnes Brasil-China". A alta nos preços foi um fator determinante do boom das commodities. O preço médio da saca de soja subiu $232,84 \%$, passando de US $\$ 13,88$ em 2006 para US $\$ 35,09$ em 2012, quando começou a cair, até chegar a US $\$ 22,34$ em 2017, uma variação negativa de 63,67\% (Centro de Estudos Avançados em Economia Aplicada, 2017). A produção de soja no Brasil expandiu-se a uma taxa anual média de crescimento de $6,7 \%$ entre as safras 2000 / 01 e 2015 / 16, com o volume de grãos saltando de 38,4 para 95,4 milhões de toneladas no período. A área plantada cresceu a uma taxa de $6.2 \%$ ao ano, indo de 14 para 33,2 milhões de hectares. E a produtividade cresceu a uma taxa anual média de $0,7 \%$ ao ano (Companhia Nacional de Abastecimento, 2017). Um conjunto de tecnologias (sementes transgênicas, plantio direto, uso de agroquímicos etc.) contribuiu para estes resultados. Mas a incorporação de mais terras à produção de soja foi um fator decisivo, já que a taxa de crescimento da área plantada foi bem superior à da produtividade. Sua progressiva expansão geográfica é um reflexo direto disso. Resulta que a produção de soja atualmente cobre $53 \%$ da área total de grãos do Brasil. Como se vê na Figura 1, o seu cultivo tem se concentrado nas regiões Centro-Oeste e Sul, onde estão os cinco maiores estados produtores: Mato Grosso, Paraná, Rio Grande do Sul, Goiás e Mato
Grosso do Sul. Não obstante, ao longo do período mais recente tem havido um grande e notável avanço do cultivo de soja na direção do Norte e do Nordeste, na região chamada de Mapitoba, um acrônimo para a área fronteiriça que engloba partes dos estados do Maranhão, Piauí, Tocantins e Bahia.

A importância e o significado do fenômeno que é a expansão da soja ficam ainda mais evidentes quando se observa em termos monetários, conforme se vê na Tabela 1. O Valor Bruto de Produção (VBP) da soja no Brasil cresceu a taxa anual média de $12,61 \%$ entre 2000 e 2015, uma taxa de crescimento extraordinária comparada ao PIB total do País no mesmo período, que foi de apenas 2,81\%, devido à desaceleração da economia em 2014, desde quando entra em grave recessão. Ou mesmo do próprio agronegócio, que cresceu a uma taxa similar de $2,84 \%$, devido ao baixo desempenho dos ramos industriais e dos serviços para a agropecuária; essa que por sua vez cresceu a uma taxa mais expressiva, de $4,58 \%$, entre 2000 e 2015. Consequentemente, a parcela do VBP da soja no total do PIB agropecuário nacional, que em 1996 era de 9,4\% (Hirakuri \& Lazzarotto, 2014), subiu excepcionalmente a $43 \%$ em 2000 , só para cair a $5,22 \%$ em 2001, e desde então elevar-se continuamente até alcançar 23,92\% em 2015. Do mesmo modo, a parcela do VBP da soja no PIB total do Brasil passou de 0,28\% em 2001 para $1,53 \%$ em 2015 , e de $1,28 \%$ para $7,13 \%$ no PIB do agronegócio no mesmo período.

Além da oferta, é preciso contextualizar o comportamento da demanda pela soja brasileira. O Brasil conta com 16\% da capacidade de esmagamento global de soja, assim como a Argentina (também 16\%), os EUA com 19\% e a China, 28\%. Em 2013, 47,4\% da soja produzida no Brasil destinou-se ao mercado doméstico para a fabricação de farelo, óleo e biodiesel, sendo que $52 \%$ do farelo e $23 \%$ do óleo foram exportados, e todo o biodiesel foi para consumo interno (Companhia Nacional de Abastecimento, 2017). Três fatores explicam essa forte demanda doméstica por soja: a substituição massiva da gordura animal e da manteiga por óleo vegetal e margarina nos hábitos alimentares; o Programa Nacional de Produção e Uso de Biodiesel (PNPB), que exige mistura de 7\% na composição do combustível e deve chegar a $10 \%$ em 2020; e o uso de farelo na fabricação de ração para frangos e suínos em sistemas de Cafo, integração vertical e contratos (Wesz, 2016). 
Figura 1. Expansão das áreas com lavouras de soja no Brasil por microrregião

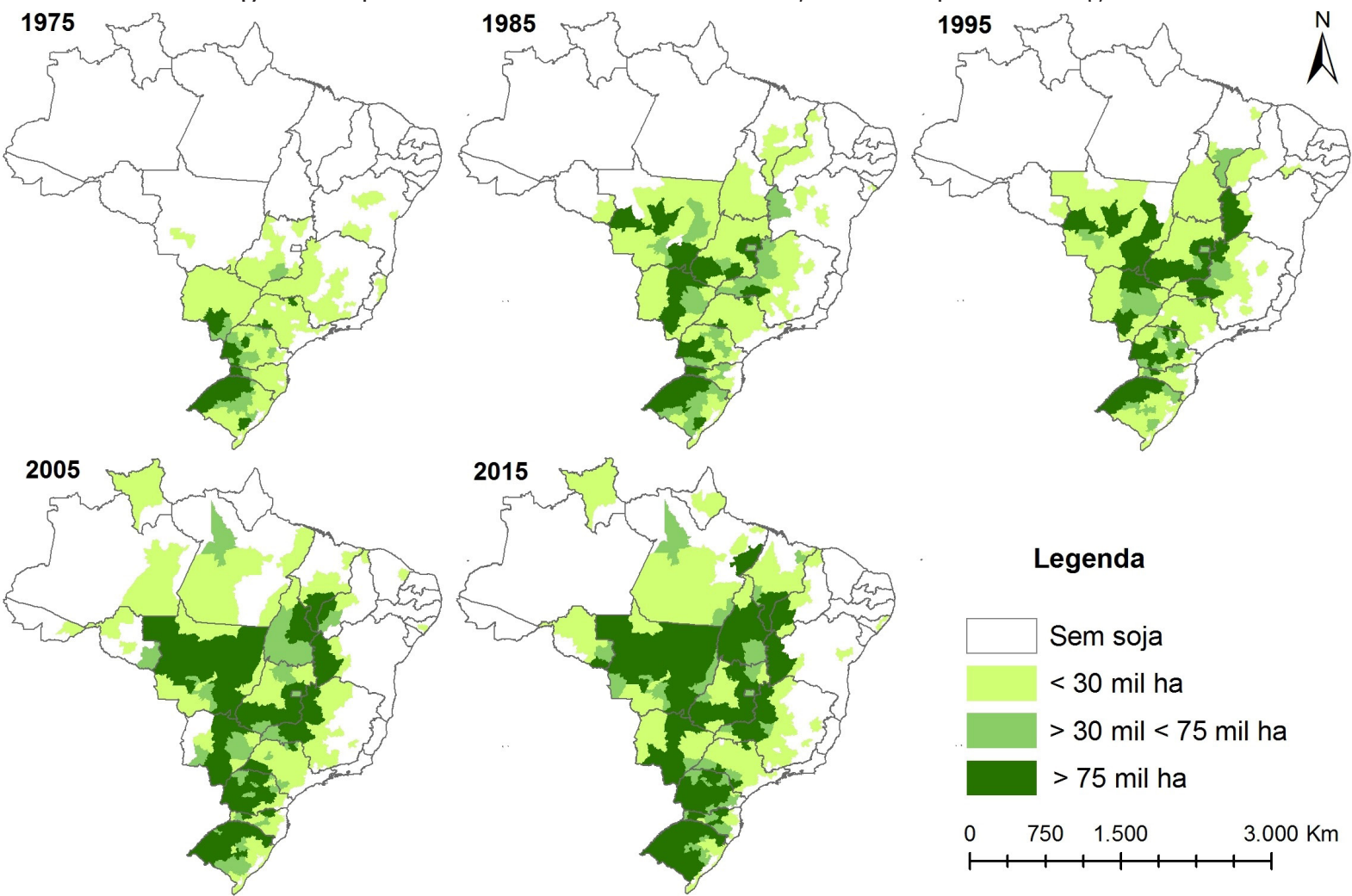

Fonte: Elaborado por Valdemar J. Wesz Jr. com dados do IBGE. Apoio Grupo de Estudos sobre Mudanças Sociais, Agronegócio e Políticas Públicas.

Tabela 1. Indicadores econômicos do complexo soja no Brasil, 2000-2015 (R\$ milhões).

\begin{tabular}{ccccccccccc}
\hline Ano & $\begin{array}{c}\text { PIB Total } \\
(\mathbf{A})\end{array}$ & $\begin{array}{c}\text { Agronegócio } \\
\text { (B) }\end{array}$ & $\begin{array}{c}\text { Agropecuário } \\
\text { (C) }\end{array}$ & $\begin{array}{c}\text { VBP Soja } \\
\text { (D) }\end{array}$ & B/A (\%) & C/A (\%) & C/B (\%) & D/A (\%) & D/B (\%) & D/C (\%) \\
\hline 2000 & $3,916,915$ & 844,595 & 200,915 & 86,587 & 21.56 & 5.13 & 23.79 & 2.21 & 10.25 & 43.10 \\
2001 & $3,971,356$ & 859,349 & 210,150 & 10,979 & 21.64 & 5.29 & 24.45 & 0.28 & 1.28 & 5.22 \\
2002 & $4,092,620$ & 935,038 & 235,161 & 17,233 & 22.85 & 5.75 & 25.15 & 0.42 & 1.84 & 7.33 \\
2003 & $4,139,310$ & 996,142 & 262,967 & 28,585 & 24.07 & 6.35 & 26.40 & 0.69 & 2.87 & 10.87 \\
2004 & $4,377,733$ & $1,021,589$ & 260,696 & 32,628 & 23.34 & 5.96 & 25.52 & 0.75 & 3.19 & 12.52 \\
2005 & $4,517,914$ & 974,006 & 235,277 & 21,750 & 21.56 & 5.21 & 24.16 & 0.48 & 2.23 & 9.24 \\
2006 & $4,696,913$ & 978,414 & 230,264 & 18,471 & 20.83 & 4.90 & 23.53 & 0.39 & 1.89 & 8.02 \\
2007 & $4,982,009$ & $1,055,633$ & 258,316 & 25,795 & 21.19 & 5.18 & 24.47 & 0.52 & 2.44 & 9.99 \\
2008 & $5,235,803$ & $1,140,691$ & 296,216 & 39,077 & 21.79 & 5.66 & 25.97 & 0.75 & 3.43 & 13.19 \\
2009 & $5,229,215$ & $1,074,685$ & 273,736 & 37,988 & 20.55 & 5.23 & 25.47 & 0.73 & 3.53 & 13.88 \\
2010 & $5,622,882$ & $1,155,704$ & 303,626 & 37,333 & 20.55 & 5.40 & 26.27 & 0.66 & 3.23 & 12.30 \\
2011 & $5,842,693$ & $1,215,615$ & 339,487 & 50,369 & 20.81 & 5.81 & 27.93 & 0.86 & 4.14 & 14.84 \\
2012 & $5,954,755$ & $1,180,519$ & 329,845 & 50,466 & 19.82 & 5.54 & 27.94 & 0.85 & 4.27 & 15.30 \\
2013 & $6,134,207$ & $1,241,738$ & 359,355 & 68,934 & 20.24 & 5.86 & 28.94 & 1.12 & 5.55 & 19.18 \\
2014 & $6,140,597$ & $1,262,364$ & 374,607 & 84,390 & 20.56 & 6.10 & 29.68 & 1.37 & 6.69 & 22.53 \\
2015 & $5,904,331$ & $1,267,241$ & 377,672 & 90,357 & 21.46 & 6.40 & 29.80 & 1.53 & 7.13 & 23.92 \\
Var \% & 2.90 & 2.70 & 4.68 & 12.60 & 21.43 & 5.61 & 26.22 & 0.85 & 4.00 & 15.09 \\
\hline
\end{tabular}

Fonte: Centro de Estudos Avançados em Economia Aplicada (2017); Instituto Brasileiro de Geografia e Estatística (2017), elaborado pelos autores. 
No entanto, mesmo com a importante demanda por soja processada no mercado doméstico, mais da metade da soja produzida no Brasil tem se destinado à exportação na forma de grãos in natura. As exportações de soja cresceram a uma taxa de $8,8 \%$ ao ano entre os biênios de 2000/2001 e 2013/2014, passando de 15,5 para 44,5 milhões de toneladas. Com $41 \%$ de toda a soja ofertada mo mercado global e 2013, o Brasil é hoje o maior exportador de soja em grãos do mundo, seguido pelos EUA, com 39,3\%, e a Argentina, com $7,3 \%$. O valor das suas exportações alcançou o patamar de US\$ 30,961 bilhões em 2013, o equivalente a 31\% do valor das exportações do agronegócio e 12,8\% das exportações totais do País, sendo responsável por 37\% do saldo comercial brasileiro (Hirakuri \& Lazzarotto, 2014). A China, como mostra a Figura 2, tem se constituído como o maior comprador da soja brasileira. Isso está alterando completamente a configuração e a dinâmica global do mercado de soja. Em 2003, 54\% das exportações de soja em grãos do Brasil ainda foram para a Europa e somente 30\%, para a China. Mas em 2013 o percentual da Europa caiu para 12\%, enquanto a China passou a receber espantosos $75 \%$ da soja embarcada do Brasil, sendo que mais de $95 \%$ é na forma de grãos (Oliveira \& Schneider, 2016). De fato, conforme indica a própria noção de "complexo soja-carnes Brasil-China", há uma dependência mútua entre a oferta e a demanda de soja dos dois países, todavia com melhor equilíbrio para a China, que tem fontes de oferta mais diversificadas do que as fontes de demanda que o Brasil tem (Wilkinson \& Wesz Junior, 2013).

O boom da soja e a expansão da fronteira agrícola que ela impulsiona são as principais forças por trás da chamada "economia e sociedade do agronegócio", formada a partir da migração dos "colonos" do Sul na sua marcha para o Centro-Oeste (Herédia et al., 2010; Delgado, 2012). Há questionamentos da narrativa que vincula a soja exclusivamente às grandes fazendas de produção capitalista em larga escala, frente à existência de uma variedade de "estilos de agricultura familiar" que também planta soja (Vennet et al., 2014). Embora isso não deva ser negligenciado, a concentração da produção é, todavia, a tendência dominante. Dados do Censo Agropecuário de 2006, apesar de desatualizados, servem para ilustrar. Dos 1.346,649 de estabelecimentos que produziram soja naquele ano, 6.080 unidades de 1.000 a 2.500 e mais ha produziram $49,92 \%$ do total; 5.674 unidades de 500 a menos de 1.000 ha produziram $14,06 \% ; 24.787$ unidades de 100 a menos de 500 ha produziram $20,13 \% ; 22.783$ unidades de 50 a menos de 100 ha produziram 5,26\%; e o restantes $1.287,325$ com menos de 50 ha produziram somente 10,63\% (Escher, 2016).

Disso são depreendidas duas implicações chave. A primeira, à que voltaremos nas conclusões, diz respeito à importância do complexo soja na sustentação da balança comercial (Figura 3). Num quadro de progressiva deterioração da estrutura industrial e de baixa competitividade global da economia brasileira em setores de mais alta tecnologia e agregação de valor por empresas nacionais, as exportações de recursos naturais, não só através da soja e do agronegócio, mas também da mineração (o ramo do petróleo possui características e dinâmicas distintas), para o bem ou para o mal tem literalmente "salvado a lavoura". Porém, autores como Delgado (2012) e outros têm mostrado que isso não vem sem custos ou consequências negativas, especialmente aquelas ligadas à especialização regressiva da economia

Figura 2. Exportações brasileiras de soja em grãos - mundo e China.

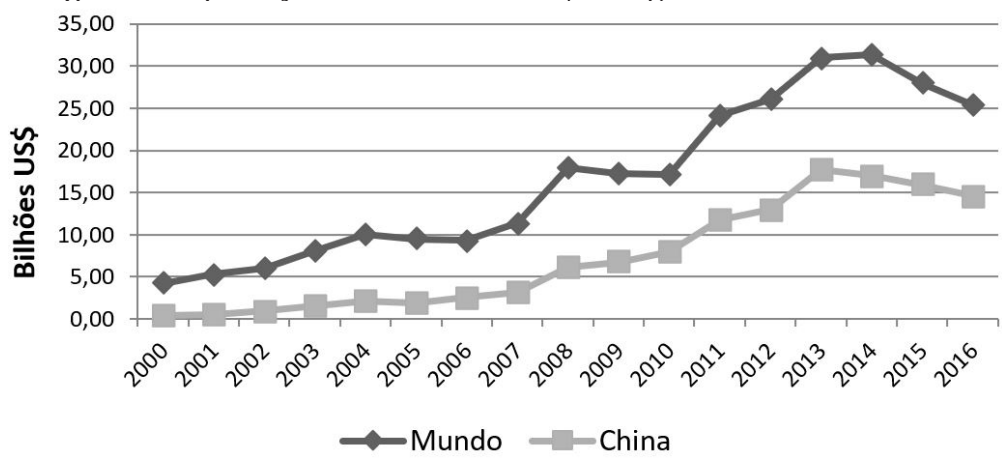

Fonte: Brasil (2017a), elaboração dos autores. 
Figura 3. Indicadores da balança comercial do Brasil, 2000-2016.

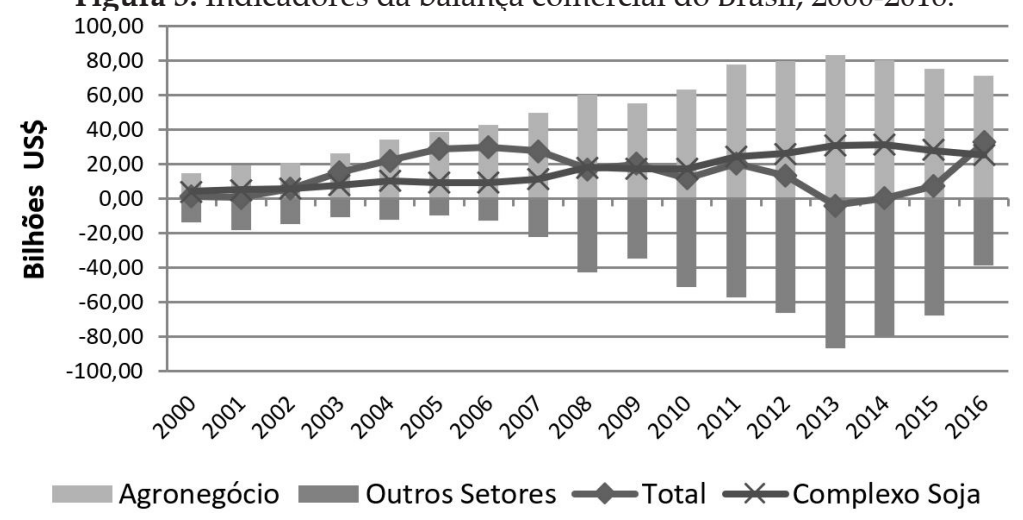

Fonte: Brasil (2017a, b), elaboração dos autores.

brasileira e ao poder político de setores conservadores do agronegócio no âmbito da bancada ruralista.

A segunda diz respeito à valorização dos preços da terra e à concentração da propriedade fundiária no Brasil no contexto de "global land grabbing" 9 (Wilkinson et al., 2013; Borras et al., 2012, 2016). A alta nos preços dos alimentos em 2008 aqueceu a demanda por terra em países exportadores como o Brasil, induzindo a elevação no nível de preços dos ativos fundiários, que passaram de uma média de R\$ 4.756 por hectare em 2010 para R\$10.083 em 2015, aumento de 112\% em nível nacional. Com efeito, o aumento foi maior na região Centro-Oeste (254\%), onde está o estado de Mato Grosso, seguido pelo Norte $(252 \%)$ e o Nordeste (206,6\%), áreas que fazem parte do Mapitoba, e depois o Sul (205\%) e o Sudeste (194\%), áreas de ocupação mais antiga ${ }^{10}$. Isso estimulou novas formas de apropriação das rendas destes ativos, alterando as funções produtivas e patrimoniais das atividades agropecuárias: primeiro para fins produtivos e depois para fins especulativos, orientados cada vez mais pela dominância da lógica do capital financeiro, como

9 Antes do debate internacional sobre "land grabbing", no Brasil já se falava de "grilagem" e "estrangeirização" das terras. Há hoje no Brasil 34.371 imóveis rurais ( $0,7 \%$ do total) em propriedade de estrangeiros, cobrindo 4,3 milhões de ha $(0,79 \%$ do total) (Wilkinson et al., 2013). Segundo o site Land Matrix, de 2000 para cá houve 61 anúncios de compra de terra por estrangeiros no Brasil, sendo que os principais são Estados Unidos (12), Canadá (10), Argentina (10), Japão (8), Holanda (5), China (5) e Reino Unido (4).

10 Nota-se que há variações regionais no preço das terras dentro de um mesmo estado. Conforme averiguado em trabalho de campo, no norte de Mato Grosso, região de Sorriso, às bordas da BR 163, o hectare pode chegar a 1.000 sacas de soja (R\$ 58 a saca, cotação de 16 de agosto de 2017), nas regiões periféricas da BR 163, pode variar entre 350 e 600 sacas e, no vale do Araguaia pode-se pagar apenas 80 sacas/ha. evidencia a forte correlação entre o preço do hectare de terra com o preço da saca de soja (0.923) e com o índice Bovespa (0.886) (Flexor \& Leite, 2017). Por um lado, é difícil associar a enorme concentração fundiária do Brasil - o índice de Gini terra é de 0,856 - exclusivamente à ação do capital estrangeiro, haja vista o papel histórico das próprias elites rurais nacionais na configuração de uma estrutura agrária extremamente desigual. Por outro, a "financeirização da agricultura", com cada vez mais os atores do mercado financeiro (empresas e fundos de investimentos internacionais e imobiliárias rurais domésticas) atuando no mercado de terras na esteira do boom das commodities, indica a necessidade de maior atenção acadêmica e política ao assunto (Wilkinson et al., 2013; Balestro \& Lourenço, 2014).

\section{Tendências dos investimentos chineses no agronegócio brasileiro}

O último ponto nos traz para além das questões tradicionais de comércio agrícola internacional e introduz de forma decisiva o papel dos investimentos chineses no agronegócio brasileiro. Em suma, o estado chinês, através da política de going out, apoia as empresas chinesas a investir em terras e recursos agrícolas, a montar operações de processamento, a construir capacidades logísticas, a cooperar com e a adquirir firmas estrangeiras, a fim de expandir o alcance global das empresas estatais e privadas da China a ponto de começar a ameaçar seriamente o poder das corporações transnacionais líderes do setor agroalimentar do Atlântico Norte. A partir do Quadro 2 é possível observar três fases da internacionalização das 


\begin{tabular}{|c|c|c|c|c|c|c|c|c|c|c|}
\hline 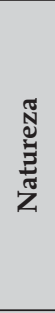 & 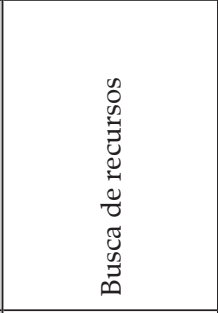 & 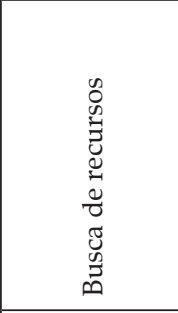 & 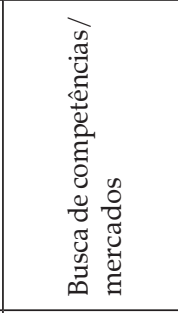 & 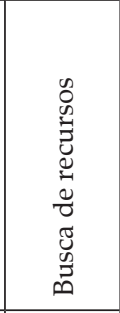 & 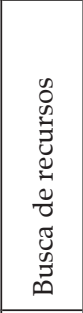 & 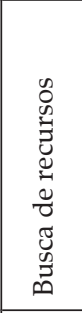 & 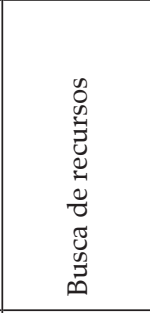 & 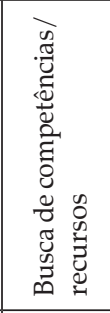 & 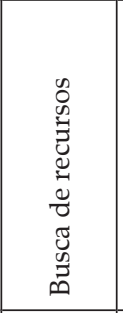 & 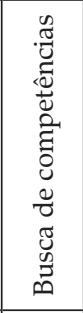 \\
\hline 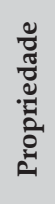 & 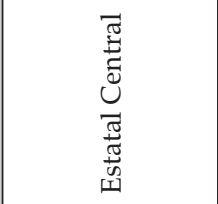 & 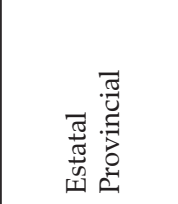 & 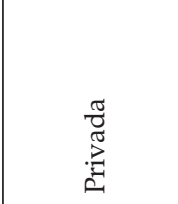 & 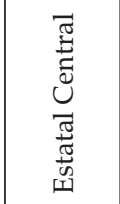 & $\begin{array}{l}\frac{\pi}{0} \\
\stackrel{\pi}{\Xi} \\
\tilde{D}\end{array}$ & 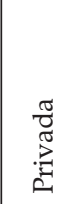 & 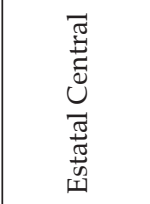 & $\begin{array}{l}\frac{\pi}{\pi} \\
\stackrel{\pi}{\pi}\end{array}$ & 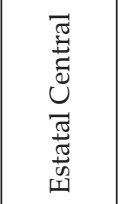 & 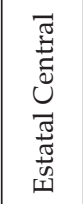 \\
\hline $\begin{array}{l}\frac{\pi}{\pi} \\
\frac{\pi}{\pi} \\
\frac{\pi}{\pi} \\
\frac{\pi}{0} \\
\sum\end{array}$ & 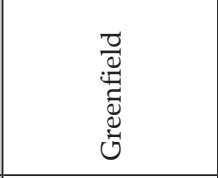 & 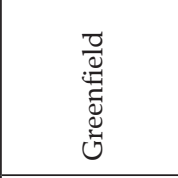 & 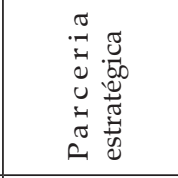 & $\begin{array}{l}\mathbb{8} \\
\\
\end{array}$ & 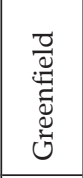 & 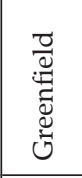 & 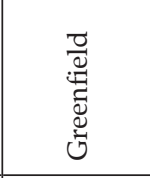 & 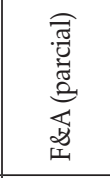 & 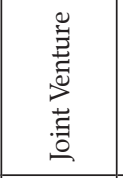 & 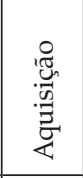 \\
\hline 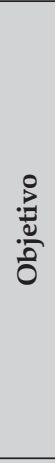 & 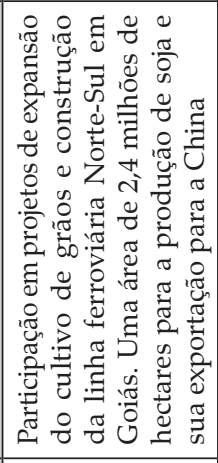 & 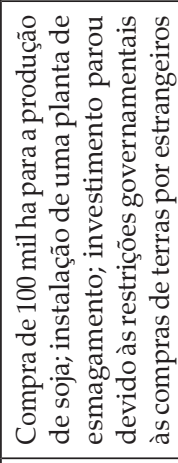 & 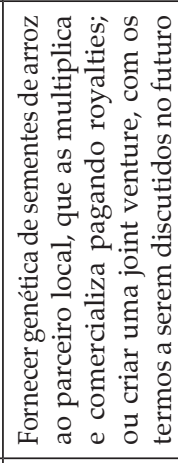 & 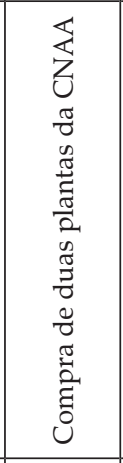 & 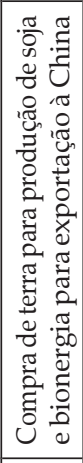 & 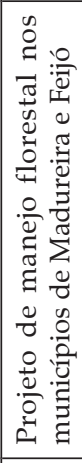 & 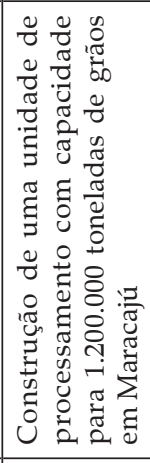 & 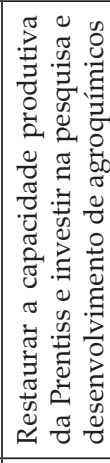 & 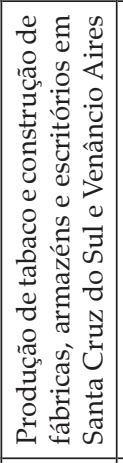 & 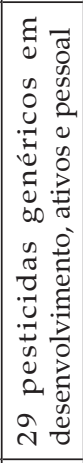 \\
\hline 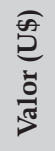 & $\vec{a}$ & 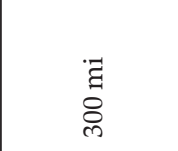 & $\frac{\ll}{z}$ & $\frac{\varangle}{z}$ & $\frac{\ll}{z}$ & $\begin{array}{l}\text { పี } \\
\text { ̊ี }\end{array}$ & 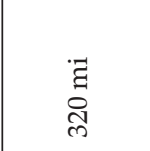 & $\frac{\varangle}{z}$ & $\begin{array}{l}\text { ¿ี } \\
\text { 。् }\end{array}$ & $\frac{\varangle}{z}$ \\
\hline 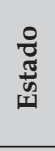 & ○ & 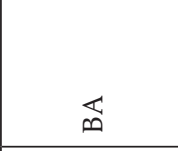 & $\frac{\varangle}{z}$ & $\begin{array}{l}0 \\
\sum \\
0 \\
0\end{array}$ & $\overleftrightarrow{\infty}$ & 这 & $\sum_{\Sigma}^{\infty}$ & $\cong$ & $\cong$ & $\begin{array}{l}\mathscr{\imath} \\
\stackrel{a}{a}\end{array}$ \\
\hline $\begin{array}{l}\stackrel{0}{60} \\
\frac{0}{5} \\
\frac{5}{5}\end{array}$ & 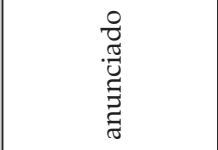 & 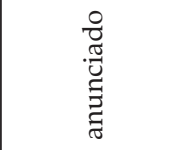 & $\frac{\ll}{z}$ & $\begin{array}{l}0 \\
\frac{8}{0} \\
\tilde{\sigma} \\
\Xi \\
\Xi \\
\Xi\end{array}$ & 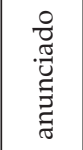 & 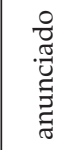 & 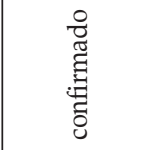 & 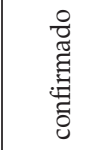 & 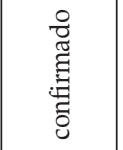 & 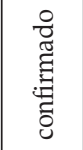 \\
\hline 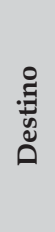 & $\begin{array}{l}: 0 \\
: 00 \\
0 \\
0 \\
0 \\
0 \\
0 \\
0 \\
0 \\
0\end{array}$ & $\frac{\varangle}{\mathrm{z}}$ & 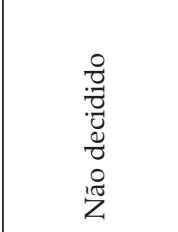 & 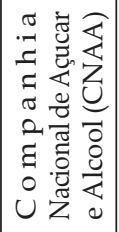 & 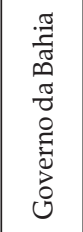 & $\frac{\varangle}{z}$ & $\frac{\varangle}{\mathrm{z}}$ & 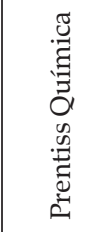 & 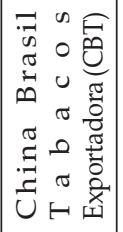 & 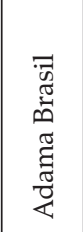 \\
\hline 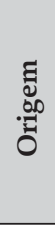 & 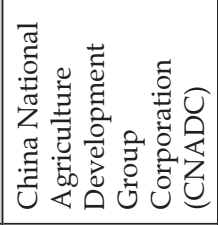 & 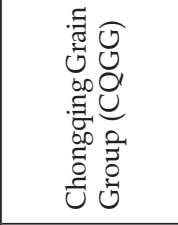 & 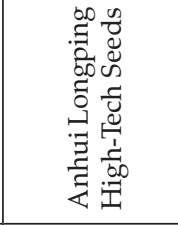 & $\begin{array}{l}\text { ग्ञ } \\
0 \\
0 \\
0 \\
0 \\
0\end{array}$ & 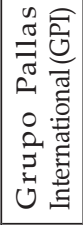 & 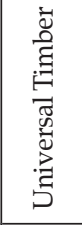 & 芯 & 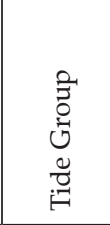 & 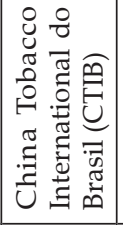 & 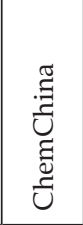 \\
\hline$\stackrel{8}{\&}$ & $\overrightarrow{\vec{\sigma}}$ & $\overrightarrow{\vec{\sigma}}$ & $\vec{\nabla}$ & $\overrightarrow{\widetilde{N}}$ & $\overrightarrow{\widetilde{N}}$ & 곡 & $\stackrel{m}{\stackrel{N}{N}}$ & $\stackrel{\vec{\sim}}{\stackrel{\sim}{\sim}}$ & 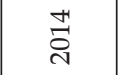 & $\underset{\sim}{\stackrel{\sim}{\sim}}$ \\
\hline
\end{tabular}




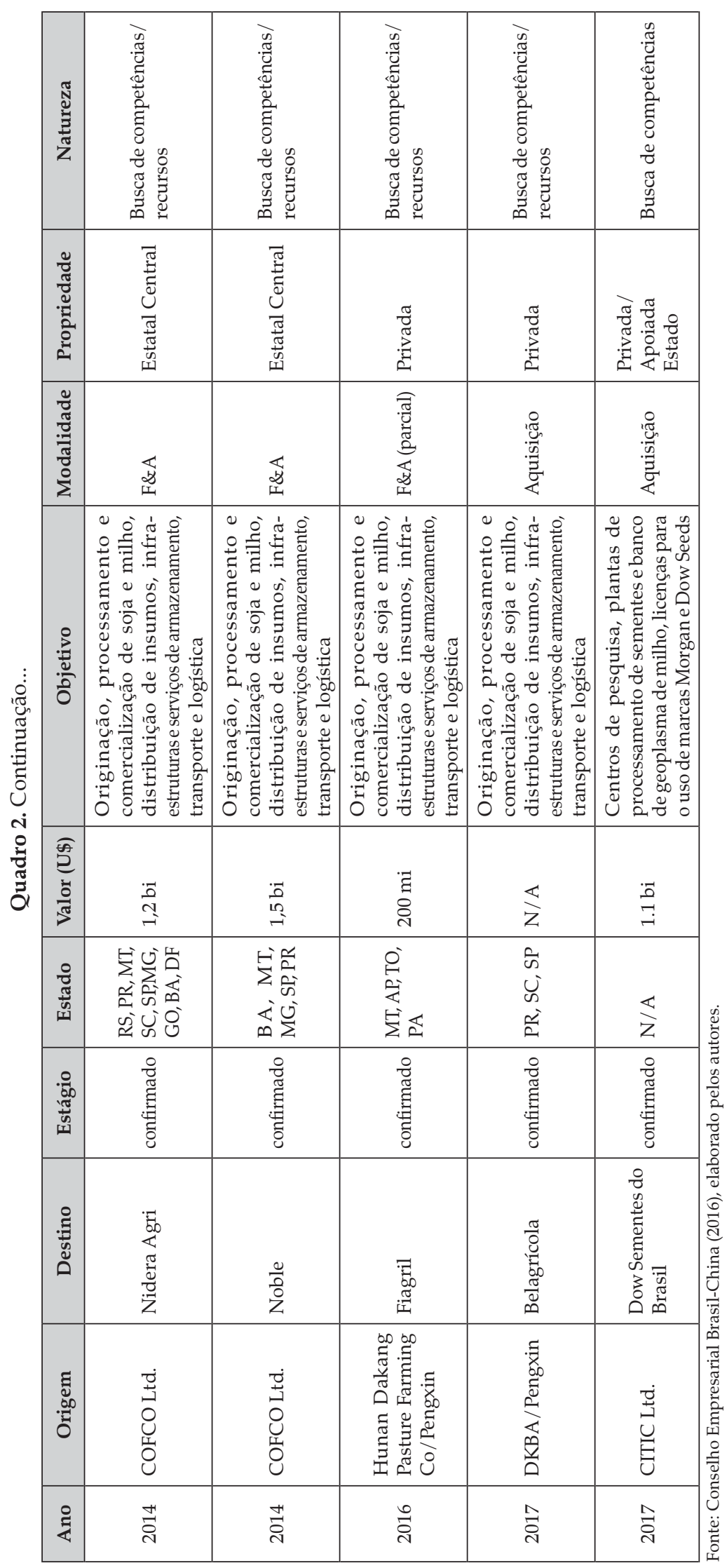


empresas chinesas com IDEs no agronegócio e estudar a sua evolução e tendências no Brasil.

A primeira fase, que vai da primeira metade dos anos 2000 e até 2008 , é marcada pela emergência da China como um player global no mercado de commodities. Apesar de também ser um grande produtor de commodities (carvão e petróleo, alumínio e aço, trigo, arroz, milho e soja etc.), sua produção doméstica não se manteve ao passo da sua demanda (Coates \& Luu, 2012). Nesse período, fica clara a dependência da China em relação à importação de alimentos, energia e matérias-primas agrícolas e minerais. A sua demanda, junto a outros fatores, será uma das principais forças por trás da escalada sem precedentes no nível de preços das commodities. "A construção de uma base internacional de supridores destas commodities constitui possivelmente a face mais visível da internacionalização das firmas chinesas e da ampla iniciativa do governo chinês nas relações internacionais" (Medeiros, 2011, p.209).

Poder-se-ia argumentar que essa fase tenha ido até 2012, quando o crescimento chinês começa a desacelerar (de uma média de $10 \%$ para cerca de $6,5 \%$ ao ano) e o boom no preço das commodities chega ao fim, voltando a patamares "normais", apesar de a demanda seguir intensa. Mas o que se quer enfatizar é que, embora a política de going out já existisse desde 2001, é a partir do estouro da crise de 2008 que inicia a segunda fase, quando se intensifica a saída das empresas chinesas no setor de agronegócios, particularmente na compra de largas porções de terra nos países do sudeste asiático, África e América Latina, incluindo o Brasil. Nesse período, há uma extensiva atenção da mídia, ONGs e acadêmicos discutindo se a China não estaria tornando-se uma potência "neocolonial" e um dos principais atores na onda de "global land grabs". Contudo, o que estudos mais criteriosos com as evidências mostraram até agora é que, apesar do discurso de medo de que a "China está tomando o mundo", os investimentos em terras dos chineses são bem menores do que os de outros países, como os do Golfo no Oriente Médio, ou mesmo da Europa ou dos Estados Unidos. De qualquer maneira, certo é que mesmo havendo uma diversidade de atores (empresas estatais centrais, estatais provinciais, privadas, indivíduos ricos e fundos de investimento), o caráter dos investimentos chineses em terra é de "terceirização desenvolvimentista", em que o estado joga um papel crucial no planejamento, na intervenção e na regulação de todo o processo (Hofman \& Ho, 2012).

No caso específico do Brasil, avaliações um tanto exageradas informaram que os chineses adquiriram exorbitantes 7 milhões de hectares (Acioly et al., 2010), mas estudos empíricos mais aprofundados (Oliveira, 2015; Wilkinson et al., 2015) identificaram apenas uns poucos projetos com informações confiáveis. Em 2007, a empresa Pacific Century Group's, baseada em Hong Kong, adquiriu 27.397 ha em uma participação minoritária com a argentina CalyxAgro. E a firma privada Zhejiang Fudi Agriculture Co, em parceira com a estatal Beidahuang/ Heilongiiang State Farm Company, adquiriu cerca de 600 ha no Rio Grande do Sul e 16.000 ha no Tocantins, entre 2007 e 2008. Porém, ao se depararem com dificuldades operacionais, elas acabaram por vender a maioria dos ativos para a empresa Universo Verde, subsidiária da estatal provincial Chongqing Grain Group (CGG), em 2011. No mesmo ano, a CGG tentou comprar 200.000 ha no oeste da Bahia para produzir soja, mas o governo brasileiro aplicou restrições jurídicas à aquisição de terras por estrangeiros que já existiam desde o ano anterior, e a firma acabou comprando uma área de 52.000 ha, anunciando as construções de uma planta de esmagamento de soja e de uma fábrica de fertilizantes em Barreiras (BA), bem como de infraestruturas de transporte ferroviário e armazenagem, até hoje não realizadas por problemas administrativos, ambientais e sociais (ocupação do MST). A empresa privada Sanhe Hopeful Grain and Oil Co e a estatal CNADG (China National Agriculture Development Group) anunciaram a compra de vultosos 2,4 milhões de ha e a construção de infraestruturas de transporte ferroviário e armazenagem em Goiás, num total de US\$ 7,5 bilhões em 10 anos. Mas o que de fato se realizou foi apenas a participação com $20 \%$ na construção de um terminal portuário em Santa Catarina, que está parada pela falta de licença ambiental. E o grupo Pallas International anunciou interesse ao governo da Bahia na compra de 250.000 ha para a produção de soja visando exportação, igualmente sem confirmação.

Em contraste, investidores da Europa e dos Estados Unidos, e de países como Argentina e Japão, têm entrado com bastante força na compra de grandes porções de terra para a produção direta no cultivo de soja em larga escala para a exportação. Grupos empresariais agrícolas destes países, como Cresud/Brasilagro, Adecoagro, SLC Agrícola, El Tejar, TIAA-CREF, Multigrain/Xingu 
Agro e V-Agro, adquiriram em seu conjunto mais de 750.000 ha de terra no Brasil desde 2008. Segundo Oliveira (2015), apesar de os IDEs chineses na compra de terras serem menores do que desses outros países, eles receberam atenção negativa desproporcional na mídia, críticas alarmistas de intelectuais de diversas cores ideológicas, resistência dos movimentos sociais e oposição da bancada ruralista, cujos membros na verdade querem oportunisticamente posicionar-se como parceiros necessários para a concretização destes investimentos. Entrevistados de Escher et al. (2017), em trabalho de campo em Mato Grosso, aludiram que a pressão dos chineses para comprar terras deve voltar se avançarem no parlamento as medidas pela liberalização da compra de terras por estrangeiros, o que por ora está em aberto, mas parece confirmar a razoabilidade da hipótese de Oliveira (2015).

Por fim, na terceira fase, que vai de 2012 até os dias correntes, observa-se uma mudança de estratégia, em que a orientação dos IDEs chineses se desloca de operações greenfield na compra de terras para o cultivo direto e se direciona à operações de fusão e aquisição de ativos de empresas de agronegócios com o objetivo precípuo de controlar as cadeias de valor de determinadas commodities em certas regiões-chave, contando inclusive com a construção de infraestruturas de logística, transporte e armazenagem. No nível internacional, os processos de expansão de empresas chinesas têm atraído atenção e publicidade. A já comentada Shanghui, originalmente uma empresa estatal que em 2006 teve seu capital aberto, em 2009 obteve investimentos da Goldman Sachs e em 2013 já contava com capital de seis fundos de investimento chineses, quando adquiriu a americana Smithfield por US $\$ 7,1$ bi e tornou-se a maior empresa de carne suína do mundo. E a estatal ChemChina, que em 2017 adquiriu a suíça Syngenta e hoje controla 8\% do mercado de sementes e $20 \%$ do mercado mundial de pesticidas. Este negócio ocorre dentro de um processo mais amplo de consolidação corporativa do setor de insumos, incluindo a aquisição da Monsanto pela Bayer (que controlará 29\% do mercado de sementes e $26 \%$ do mercado de pesticidas) e a fusão entre a Dow e a Dupont (que controlará $25 \%$ do mercado de sementes e 16\% do mercado de pesticidas) (Clapp, 2017).

Novamente, no caso específico do Brasil, vale a pena comentar algumas operações significativas. No ramo de insumos ocorreram negócios importantes. A Tide Group, um conglomerado de químicos e trading que abriu subsidiária no Brasil em 2010 com a intenção de trazer seus pesticidas diretamente da China para comercializar aqui, mas em face de dificuldades com regulações em 2014 acabou adquirindo a Prentiss Química, com registros e capacidade de ofertar herbicidas, inseticidas e fungicidas, no intuito de facilitar sua entrada no mercado. A CITIC Agri Fund, que em parceria com a Yuan Longping High-Tech Seeds, já no Brasil desde 2011, em 2017 adquiriu por US\$ 1,1 bi a LP Sementes, parte da Dow Brasil, para atender exigências das autoridades brasileiras a fim de efetivar a fusão entre Dow e DuPont, e inclui ativos para a produção de sementes, centros de pesquisa, um banco de germoplasma de milho, a marca Morgan e a licença temporária para a utilizar a marca Dow Sementes. E a ChemChina, que em 2011 adquiriu a israelense Adama, com duas fábricas no Brasil, cujo controle se deu a partir de 2014 junto com as licenças comerciais e canais de mercado, agora em 2017, através da Syngenta, adquiriu a Nidera Seeds da também chinesa COFCO. Outra é a China Tobacco International do Brasil (CTIB), uma subsidiária da China Tobacco International, que em 2012 estabeleceu uma parceria de 51\% com a Alliance One Brasil, cujo principal ativo é mais de 600 contratos com pequenos produtores de tabaco do Rio Grande do Sul (1/5 dos contratos da Alliance One Brasil) para exportar direto para a China.

Mas o núcleo dos IDEs chineses no agronegócio brasileiro, diretamente ligado à integração do complexo soja-carne Brasil-China, está no ramo de trading. A dinâmica do mercado de commodities agrícolas vem passando por mudanças nos últimos anos, sendo a concentração corporativa, o acirramento concorrencial e a integração vertical, horizontal e financeira das cadeias de valor as tendências definidoras do processo (Clapp, 2015). Historicamente dominado pelas quatro grandes empresas conhecidas como ABCD (ADM, Bunge, Cargill e Dreyfus), que compram e vendem grãos e outras commodities e empreendem diversas atividades, de finanças à produção, processamento, transporte e distribuição, o ramo vem sendo reestruturado com a entrada de novas firmas, sobretudo asiáticas (China, Japão, Singapura, Rússia). Em 2014, as ABCD responderam por 46\% dos grãos exportados pelo Brasil, ante 36\% das empresas da Ásia. Mas em 2015 ocorreu uma súbita inversão, quando as tradings asiáticas, incluindo a chinesa COFCO, embarcaram $45 \%$ dos grãos exportados pelo Brasil, enquanto as $\mathrm{ABCD}$ 
ficaram com 37\% (Bonato, 2016). A estatal COFCO (China National Cereals, Oils and Foodstuffs Corporation) é a maior produtora e esmagadora de soja, refinadora de óleo, produtora de alimentos processados e trader da China. Em 2014 ela adquiriu a holandesa Nidera (US\$ 1,2 bilhão) e a parte agrícola da singapuriana Noble (US\$ 1,5 bilhão), ambas com operações de larga escala no Brasil e outros países do Cone Sul, entrando para o mesmo ranking das $\mathrm{ABCD}$, que agora não são mais as "Big Four", mas as "Big Five" - já se fala das $\mathrm{ABCCD}$, sendo que o segundo $\mathrm{C}$ refere-se à COFCO. ${ }^{11}$ Com a integração da Nidera e da Noble consolidada, a COFCO já entrou dominando $11 \%$ do mercado de grãos no Brasil, e pretende chegar a $22 \%$ nos próximos cinco anos, reduzindo o market share das concorrentes e achatando as margens de lucro do ramo.

Além disso, até por volta de 2014 o grupo ABCD dominava cerca de $80 \%$ da originação de soja em Mato Grosso; atualmente domina apenas cerca de 50\%. A diferença de preço entre disponível e originado está em torno de $10 \%$. E a principal causa dessa perda de capacidade de originação por parte das $\mathrm{ABCD}$ é o ganho de capacidade por parte das firmas asiáticas, como a Multigrain/Mitsui, a Gavilon/Marubeni, a Sodrujestvo, a Olam (em parceria com a ADM), mas, sobretudo, a COFCO, que em 2017 originava cerca de $70 \%$ do volume que comercializa. Vale notar que a estatal COFCO não é a única empresa chinesa de trading entrando no Brasil via IDE. A empresa chinesa Hunan Dakang, do Grupo Pengxin, também entrou no segmento de grãos ao comprar a Fiagril em Mato Grosso e a Belagrícola no Paraná. Isso mostra como as corporações de agronegócio chinesas estão rapidamente conquistando um espaço até então exclusivamente ocupado por empresas do Atlântico Norte.

Os portos e ferrovias são os mais importantes setores de investimento em infraestrutura e logística para a agroindústria com a explosão das exportações e seu deslocamento para o norte do País. A Fiagril tem investimentos portuários que talvez sejam incorporados pela Hunan Dakang. Mas o principal investidor chinês no setor portuário é a China Communications \& Construction Company que, através da aquisição de $80 \%$ da Concremat, estabeleceu a CCC South America, visando investir nos

11 A COFCO já havia entrado também no ramo de açúcar ao adquirir duas fábricas da CNAA. Com a compra da Noble Agri adquiriu mais quatro unidades em São Paulo, sendo hoje a sexta no ranking do ramo no Brasil. portos de Miritituba, Vila do Conde e Itaqui, e no terminal de cargas no porto do Maranhão. Ainda na logística destaca-se a China Railway Construction Corporation, que em 2014 assinou acordo com a Camargo Corrêa para avaliar a formação de consórcios para a construção das ferrovias (incluindo a chamada Ferrovia Bioceânica), e em 2016 assinou acordos de intenção de investimentos com os governos de Mato Grosso e Pará (Escher et al., 2017).

\section{Conclusões}

O presente trabalho confirma a tese de Wilkinson (2009) sobre a oligopolização e internacionalização das corporações do agronegócio e das indústrias de alimentos representarem as tendências dominantes por trás da globalização dos sistemas agroalimentares de países emergentes como Brasil e China. A consolidação dos "impérios alimentares" brasileiros ${ }^{12}$ e chineses, para usar a expressão de Ploeg (2010), adquire importância estratégica porque, ao criar coalizões de interesses entre eles, atenuam o poder econômico dos países capitalistas centrais e reforçam a influência dos seus próprios estados e empresas no reordenamento do regime alimentar. A formação do complexo soja-carne China-Brasil e os discursos e narrativas construídas para justificar os interesses vetustos nos dois lados são emblemáticos. Este movimento poderia ser chamado de "momento Gramsci". É quando os interesses da agricultura capitalista, dos impérios agroalimentares e do estado se encontram e são traduzidos como "interesses nacionais", tornando-se parte constitutiva da coalizão de poder que forma um bloco hegemônico. ${ }^{13}$

No Brasil, conforme demonstra Delgado (2012), tal coalizão incorpora os interesses da burguesia agrária, dos grandes proprietários fundiários, do capital agroindustrial e das políticas macroeconômica, agrícola e de apoio à internacionalização promovidas pelo estado.

12 Sobre a internacionalização de empresas brasileiras de agronegócio, ver Escher \& Schneider (2019), entre outros.

13 No Brasil, embora tenha havido mudanças no bloco no poder desde o impeachment de Dilma Rousseff, o governo de Michel Temer e a eleição de Jair Bolsonaro, nada acusa a perda de influência do agronegócio. E na China, embora se ouça informalmente que a crise suína de 2019 pode abrir espaço para um maior apoio à produção camponesa de pequena escala, nada indica que as grandes corporações deixarão de ser apoiadas. 
Eles perseguem uma estratégia de apropriação da renda da terra advinda das vantagens comparativas dos recursos naturais como linha de frente da acumulação de capital para toda a economia. A universalidade destes interesses é justificada com um discurso que enaltece a capacidade de o agronegócio gerar os superávits comerciais necessários para preencher o fosso do balanço de pagamentos causado pelos déficits na conta de serviços ao capital estrangeiro e evitar desequilíbrios na conta corrente. A origem desta coalizão de poder, a "economia política do agronegócio", está na crise cambial de 1999, quando o governo FHC viu na ativação das exportações do setor primário uma estratégia de ajustamento à ordem neoliberal capaz de gerar saldos comerciais e controlar a inflação. Desde então o seu poder se consolidou no aparelho estatal e passou a fazer parte da base de apoio dos governos do PT, que viam a manutenção dessa aliança como inevitável para garantir "governabilidade", e inclusive sendo reforçado nos governos Temer e Bolsonaro. Sua principal forma de expressão política é a Frente Parlamentar da Agropecuária, a "bancada ruralista", de caráter conservador, que representa os interesses das organizações do patronato rural e de outras associações vinculadas aos diferentes complexos agroindustriais. No entanto, a pretensa legitimidade ideológica desta narrativa tem sido desafiada pela queda nos preços internacionais das commodities desde 2012, a crítica social ao uso abusivo de agrotóxicos e a ameaça de reprimarização e desindustrialização da economia brasileira.

E no caso chinês, segundo Schneider (2014), os interesses hegemônicos são representados por uma estratégia de acumulação de capital que inclui a agricultura industrial, os investimentos em terras e agronegócios no exterior e as transferências de terras de camponeses para empreendimentos domésticos agropecuários e imobiliários, com o apoio da política estatal de créditos e subsídios. O poder da coalizão entre agronegócio e parte da burocracia estatal na China verifica-se no fato de que, embora a maioria dos casos de contaminação ambiental e escândalos alimentares derivem de práticas típicas da agricultura capitalista e da indústria de alimentos, na imprensa oficial e das empresas é comum tomar os agricultores camponeses de "bode expiatório", considerando-os atrasados, tradicionais e ignorantes, e propor como solução a "modernização da agricultura" através da promoção de sistemas de CAFO e integração vertical, operados por corporações, como se fossem estas mais confiáveis e fáceis e monitorar e não a própria raiz dos problemas. E a defesa da universalidade destes interesses é justificada pelo discurso de que este é o único jeito de garantir alimentação em quantidade e qualidade para toda a imensa população chinesa. No entanto, a legitimidade ideológica dessa narrativa é questionável, já que a noção oficial chinesa de segurança alimentar (autossuficiência em grãos) é complicada pela sua abrangência cada vez mais restringida, com a exclusão da soja, e quem sabe até do milho, entre os grãos básicos, e pela crescente pressão sobre as importações agroalimentares advinda da "carnificação" das dietas e da escassez de água e terra agriculturável. ${ }^{14}$

Este trabalho contribui para suprir lacunas teóricas na economia política dos regimes alimentares. Segundo Wilkinson \& Goodman (2015), tal abordagem teria um foco exclusivo na agricultura como fonte de alimentação, deixando de atentar para o seu papel como fonte de matérias-primas. Como visto, antes de alimento, a soja brasileira é precisamente matéria-prima para a fabricação de ração para alimentar os porcos em sistema de CAFO na China. A abordagem também teria um olhar homogeneizante, centrado excessivamente no Norte / Ocidente, com uma relativa negligência às dinâmicas nacionais e regionais dos países do Sul/ Oriente. Novamente, a formação do complexo soja-carne Brasil-China é emblemática de um deslocamento policêntrico que reordena o regime alimentar a partir dos Brics, emulando e ao mesmo tempo desafiando o poder estabelecido das corporações transnacionais do Atlântico Norte. A agenda de pesquisas em torno dessas questões, não obstante, está longe de se esgotar.

Para finalizar, uma palavra sobre as implicações para as políticas públicas no Brasil. Enquanto a China tem uma visão clara das suas prioridades, o Brasil se encontra no momento fragilizado econômica e politicamente, o que torna tarefa difícil a consolidação de estratégias articuladas em benefício mútuo de um complexo agroalimentar tão central para os padrões de consumo que se difundem nos países emergentes. O interesse da China é que o Brasil exporte grãos in natura, cuja agregação de valor se dá dentro do seu território. Para o interesse brasileiro, todavia, a agregação de valor seria a alternativa preferida, até por razões fiscais e de emprego. Há aqui um claro conflito de interesses que só uma política industrial deliberada de favorecimento da agregação de valor em território brasileiro poderia nivelar. Para isso, no entanto, faz falta uma visão de longo prazo, que busque construir

\footnotetext{
14 A estes questionamentos, soma-se as controvérsias em torno da recente crise suína enfrentada pela China.
} 
certos consensos entre os atores e instituições envolvidos nos complexos agroindustriais sobre o seu papel na dinâmica geral da economia, bem como uma maior sensibilização a respeito da importância das questões sociais e trabalhistas, ambientais e de saúde. E mais do que isso, o Brasil precisa reencontrar uma estratégia de desenvolvimento rural que integre questões mais amplas, como geração de emprego e renda, diversidade social e produtiva da agricultura familiar, justiça social e distributiva, segurança alimentar e nutricional e sustentabilidade ambiental.

\section{Referências}

Acioly, L., Pinto, E. C., \& Cintra, M. A. M. (2010). China e Brasil: oportunidades e desafios. In R. P. F. Leão, E. C. Pinto \& L. Acioly (Eds.), A China na nova configuração global: impactos políticos e econômicos. Brasília: IPEA.

Armony, A. C., \& Strauss, J. C. (2012). From going out (zou chuqu) to arriving in (desembarco): constructing a new field of inquiry in China-Latin America interactions. China Quarterly, 209, 1-17.

Arrighi, G. (2010). Adam Smith em Pequim. Origens e fundamentos do século XXI. São Paulo: Boitempo.

Balestro, M. V., \& Lourenço, L. C. B. (2014). Notas para uma análise da financeirização do agronegócio: além da volatilidade dos preços das commodities. In A. M. Buainain, E. Alves, J. M. Silveira \& Z. Navarro. O mundo rural no Brasil do século 21. Brasília: Embrapa.

Bernstein, H. (2016). Agrarian political economy and modern world capitalism: the contributions of food regime analysis. The Journal of Peasant Studies, 43(3), 611-647.

Bonato, G. (2016, March 23). New titans on the block: ABCDs lose top Brazil grains spot to Asian rivals. Reuters. Recuperado em 20 de julho de 2017, de http: / / www. reuters.com/article/us-brazil-grains-idUSKCN0WP19V

Borras, S. M., \& Franco, J. C. (2012). Global land grabbing and trajectories of agrarian change: a preliminary analysis. Journal of Agrarian Change, 12(1), 34-59.

Borras, S. M., Franco, J. C., Goméz, S., Kay, C., \& Spoor, M. (2012). Land grabbing in Latin America and the Caribbean. The Journal of Peasant Studies, 39(3-4), 845-872.

Borras, S., Franco, J., Isakson, R., Levidow, L., \& Vervest, P. (2016). The rise of flex crops and commodities: implications for research. The Journal of Peasant Studies, 43(1), 93-115.

Branco, R. S. (2013). Raul Prebisch e o desenvolvimento econômico brasileiro recente liderado por commodities. Sociais e Humanas, 26(1), 197-207.
Brasil. Ministério da Agricultura Pecuária e Abastecimento. (2017a). Agrostat. Brasília. Recuperado em 01 de dezembro de 2017, de http:/ / sistemasweb.agricultura.gov.br/ pages / AGROSTAT.html

Brasil. Ministério do Desenvolvimento, Indústria e Comércio Exterior. (2017b). Balança comercial brasileira. Brasília. Recuperado em 01 de dezembro de 2017, de http: / / www.mdic.gov.br/

Brown, L. R. (1995). Who will feed China? Wake-up call for a small planet. New York: W.W. Norton \& Company.

Cano, W. (2012). A desindustrialização no Brasil. Economia e Sociedade, 21(Special issue), 831-851.

Centro de Estudos Avançados em Economia Aplicada CEPEA. (2017). PIB do agronegócio. São Paulo. Recuperado em 01 de dezembro de 2017, de https:/ / www.cepea. esalq.usp.br/br

China Statistical Yearbook - CSY. (2015). China Statistical Yearbook 2014. Beijing: NBSC. Recuperado em 07 de outubro de 2015, de http://www.stats.gov.cn/tjsj/ ndsj/2014/indexeh.htm

Christiansen, F. (2009). Food security, urbanization and social stability in China. Journal of Agrarian Change, 9(4), 548-575.

Clapp, J. (2014). Financialization, distance and global food politics. The Journal of Peasant Studies, 41(5), 797-814.

Clapp, J. (2015). ABCD and beyond: from grain merchants to agricultural value chain managers. Cannadian Food Studies, 2(2), 126-135.

Clapp, J. (2017). Bigger is not always better: drives and implications of the recent agribusiness megamergers. Álava, Basque Country, Critical Agrarian Studies Colloquium (Working Paper n. 2).

Coates, B., \& Luu, N. (2012). China's emergence in global commodity markets. Economic Roundup, The Treasury. Government of Australia, 1, 1-30.

Companhia Nacional de Abastecimento-CONAB. (2017). Soja Brasil. Brasília. Recuperado em 01 de dezembro de 2017, de http: / www.conab.gov.br/

Conselho Empresarial Brasil-China - CEBC. (2016). Investimentos Chineses no Brasil (2014-2015). Rio de Janeiro: CEBC.

Cousins, B., Borras, J., Sauer, S., \& Ye, J. (2018). BRICS, middle-income countries (MICs), and global agrarian transformations: internal dynamics, regional trends, and international implications. Globalizations, 15(1)

Cunha, A. M., Lélis, M. T. C., \& Bichara, J. S. (2012). O Brasil no espelho da China: tendências para o período póscrise financeira global. Revista de Economia Contemporânea, 16(2), 208-236.

Curado, M. (2015). China rising: threats and opportunities for Brazil. Latin American Perspectives, 42(6), 88-104. 
Davis, J. H., \& Goldberg, R. A. (1957). A concept of agribusiness. Boston: Division of Research. Graduate School of Business Administration, Harvard University.

Delgado, G. C. (2012). Do capital financeiro na agricultura à economia do agronegócio: mudanças cíclicas em meio século (1965-2012). Porto Alegre: Editora da UFRGS.

Demeleumeester, J. M. (2012). Ascensão chinesa: uma análise de seus impactos sobre o Brasil. 2012 (Monografia). Universidade Federal do Rio Grande do Sul, Porto Alegre.

Escher, F. (2016). Agricultura, alimentação e desenvolvimento rural: uma análise institucional comparativa de Brasil e China (Tese de doutorado). Universidade Federal do Rio Grande do Sul, Porto Alegre.

Escher, F., \& Schneider, S. (2019). Capitalismo, agricultura e desenvolvimento no Brasil: uma contribuição para o debate atual. In S. Sauer. Desenvolvimento e questões agrárias: BRICS, competição e cooperação no sul global (pp. 71-104). São Paulo: Outras Expressões.

Escher, F., Schneider, S., \& Ye, J. (2018). The agrifood question and rural development dynamics in Brazil and China: towards a protective 'countermovement'. Globalizations, 15(1), 92-113.

Escher, F., Wilkinson, J., \& Pereira, P. F. (2017). Drivers and implications of Chinese investments in Brazilian agribusiness: actors, strategies and market dynamics of the corporate food regime. Moscow: BICAS. (BICAS Conference Paper, 34).

Flexor, G., \& Leite, S. (2017). Land market and land grabbing in Brazil during the commodity boom of the 2000s. Contexto Internacional, 39(2), 393-420.

Food and Agriculture Organization - FAO. International Fund for Agricultural Development. World Food Programme. (2014). The state of food insecurity in the world. Rome: FAO.

Food and Agriculture Organization Statistics Division - FAOSTAT. Organisation for Economic Co-operation and Development - OECD. (2019). Agricultural Outlook 2019-2028. Rome: FAO. Recuperado em 24 de outubro de 2019, de https: / / stats.oecd.org/

Friedmann, H. (1991). Agrifood industries and export agriculture: the changing international division of labour. In W. Friedland, L. Busch \& F. Buttel (Eds.), The new political economy of agriculture (pp. 65-93). Boulder: Westview Press.

Friedmann, H. (2005). From colonialism to green capitalism: social movements and the emergence of food regimes. In F. H. Buttel \& P. McMichael (Eds.), New directions in the sociology of global development. Oxford: Elsevier Press.

Friedmann, H. (2009). Discussion: moving food regimes forward: reflections on symposium essays. Agriculture and Human Values, 26(4), 335-344.

Friedmann, H. (2016). Commentary: Food regime analysis and agrarian questions: widening the conversation. The Journal of Peasant Studies, 43(3), 671-692.
Friedmann, H., \& McMichael, P. (1989). Agriculture and the state system: the rise and fall of national agricultures, 1870 to the present. Sociologia Ruralis, 29(2), 93-117.

Garnett, T., \& Wilkes, A. (2014). Appetite for change: social, economic and environmental transformations in China's food system. Oxford: Food and Climate Research Network.

Goodman, D., Sorj, B., \& Wilkinson, J. (1986). Agroindústria, políticas públicas e estruturas sociais rurais: análises recentes sobre a agricultura brasileira. Revista de Economia Política, 5(4), 31-56.

Harvey, D. (2005). A brief history of neoliberalism. Oxford: Oxford Press.

Herédia, B., Palmeira, M., \& Leite, S. P. (2010). Sociedade e economia do "agronegócio" no Brasil. Revista Brasileira de Ciências Sociais, 25(74), 159-176.

Hirakuri, M. H., \& Lazzarotto, J. J. (2014). O agronegócio da soja nos contextos mundial e brasileiro. Londrina: Embrapa Soja.

Hofman, I., \& Ho, P. (2012). China's 'developmental outsourcing': a critical examination of Chinese global 'land grabs' discourse. The Journal of Peasant Studies, 39(1), 1-48.

Hollander, G. (2010). Power is sweet: sugarcane in the global ethanol assemblage. The Journal of Peasant Studies, 37(4), 699-721.

Honório, M., \& Araújo, M. P. (2014). Corrente de comércio do Brasil: rumos e desafios. Revista Ciências Sociais em Perspectiva, 13(25).

Huang, P. C. C. (2011). China's new-age small farms and their vertical integration: agribusiness of co-ops? Modern China, 37(2), 107-134.

Instituto Brasileiro de Geografia e Estatística - IBGE. (2017). Contas Nacionais. Brasília. Recuperado em 01 de dezembro de 2017, de https:/ / www.ibge.gov.br/ estatisticas-novoportal/economicas/contas-nacionais.html

International Monetary Fund - IMF. (2015). World economic outlook database. Washington, DC. Recuperado em 07 de outubro de 2015, de http:/ / www.imf.org/external/ pubs/ft/weo/2015/01/ weodata/weoselgr.aspx

Isakson, R. (2014). Food and finance: the financial transformation of agro-food supply chains. The Journal of Peasant Studies, 41(5), 749-775.

Jenkins, R. (2015). Is Chinese competition causing deindustrialization in Brazil? Latin American Perspectives, 42(5), 42-63.

Kageyama, A. (1987). O novo padrão agrícola brasileiro: do complexo rural aos complexos agroindustriais. Campinas: UNICAMP.

Kissinger, H. (2011). Sobre a China. Rio de Janeiro: Objetiva.

Lenin, V. I. (1983). O desenvolvimento do capitalismo na Rússia. São Paulo: Nova Cultural. 
McBeth, J. H., \& McBeth, J. (2010). Environmental change and food security in China. London; New York: Springer.

McKay, B., Fradejas, A. A., Brent, Z., Sauer, S., \& Xu, Y. (2017). China and Latin America: towards a new consensus of resource control. Third World Thematics, 1(5), 592-611.

McMichael, P. (2009). A food regime genealogy. The Journal of Peasant Studies, 36(1), 139-169.

McMichael, P. (2013). Food regimes and agrarian questions. Winnipeg: Fernwood Publishing.

McMichael, P. (2016). Commentary: Food regime for thought. The Journal of Peasant Studies, 43(3), 648-670.

Medeiros, C. A. (2011). A ascensão da China e as matérias primas. In Fundação Alexandre Gusmão. Brasil e China no reordenamento das relações internacionais: desafios $e$ oportunidades (pp. 209-226). Brasília: FUNAG.

Müller, G. (1981). O complexo agroindustrial brasileiro. São Paulo: FGV.

Müller, G. (1990). Observação sobre a economia política da agricultura brasileira. Rascunho, 14(14), 1-65.

Oliveira, G. L. T. (2015). Chinese and other foreign investments in the Brazilian soybean complex (BICAS Working Paper, 9). Cape Town: BRICS Initiative for Critical Agrarian Studies.

Oliveira, G. L. T. (2017). The south-south question: transforming Brazil-China agroindustrial partnership (Thesis PhD). University of California, Berkeley.

Oliveira, G. L. T., \& Schneider, M. (2016). The politics of flexing soybeans: China, Brazil and global agroindustrial restructuring. The Journal of Peasant Studies, 43(1), 167-194.

Ploeg, J. D. (2010). The food crisis, industrialized farming and the imperial regime. Journal of Agrarian Change, 10(1), 98-106.

Rangel, I. (1962). A questão agrária brasileira. Recife: Comissão de Desenvolvimento Econômico de Pernambuco.

Sauer, S., Balestro, M., \& Schneider, S. (2018). The ambivalent and shaky stance of Brazil as a regional power in Latin America. Globalizations, 15(1)

Schneider, M. (2014). Developing the meat grab. The Journal of Peasant Studies, 41(4), 613-633.

Schneider, M., \& Sharma, S. (2014). China's pork miracle? Agribusiness and development in China's pork industry. Washington: Institute for Agriculture and Trade Policy. (Global Meat Complex: The China Series).

Schneider, S., Schubert, M., \& Escher, F. (2016). Regimes agroalimentares e o lugar da agricultura familiar: uma apresentação ao debate. Mundi, 1(1), 3-23.

Sharma, S. (2014). The need for feed: China's demand for industrialized meat and its impacts. Washington: Institute for Agriculture and Trade Policy. (Global Meat Complex: The China Series).
Silva, J. G. (1998). A nova dinâmica da agricultura brasileira (2. ed.). São Paulo: Editora da Unicamp.

Vennet, B., Schneider, S., \& Dessein, J. (2014). Different farming styles behind the homogeneous soy production in southern Brazil. The Journal of Peasant Studies, 43(2), 396-418.

Vergara-Camus, L., \& Kay, C. (2017). The agrarian political economy of leftwing governments in Latin America: agribusiness, peasants, and the limits of neodevelopmentalism. Journal of Agrarian Change, 17, 415-437.

Weis, T. (2013). The meat of the global food crisis. The Journal of Peasant Studies, 40(1), 65-85.

Wesz, V. J. (2016). Strategies and hybrid dynamics of soy transnational companies in the southern cone. The Journal of Peasant Studies, 43(2), 1-27.

Wilkinson, J. (2006). Network theories and political economy: from attrition to convergence? In T. Marsden \& J. Murdoch (Eds.), Between the local and the global. Research in rural sociology and development (pp. 11-38, vol. 12). Oxford, UK: JAI Press.

Wilkinson, J. (2009). Globalization of agribusiness and developing world food systems. Monthly Review, 61(4), 29.

Wilkinson, J., \& Goodman, D. (2015). Food regime analysis: a reassessment. In G. Allaire \& D. Benoit (Eds.), La grande transformation de l'agriculture vint ans après. Versailles: Éditions Quae.

Wilkinson, J., \& Wesz Junior, V. J. (2013). Underlying issues in the emergence of China and Brazil as major global players in the new South-South trade and investment axis. International Journal of Technology Management $\mathcal{E}$ Sustainable Development, 12(3), 245-260.

Wilkinson, J., Reydon, B., \& Di Sabbato, A. (2013). Concentration and foreign ownership of land in Brazil in the context of global land grabbing. Canadian Journal of Development Studies, 33(4), 417-438.

Wilkinson, J., Wesz, V. J., \& Lopane, A. (2015). Brazil, the Southern cone, and China: The agribusiness connection (BICAS Working Paper, 16). Capetown: BICAS.

World Bank - WB. (2019). Indicators. Washington, DC. Recuperado em 24 de outubro de 2019, de http: / / data. worldbank.org/indicator

Xu, Z., Zhang, W., \& Li, M. (2014). China's grain production. Monthly Review, 66(1), 25-37.

Yan, H., Cui, Y., \& Bun, K. H. (2016). China's soybean crisis: the logic of modernization and its discontents. The Journal of Peasant Studies, 43(2), 373-395.

Zhou, Z. (2010). Achieving food security in China: past three decades and beyond. China Agricultural Economic Review, 2(3), 251-275. 